\title{
Steel-concrete frames under the column loss scenario: An experimental study
}

\author{
Riccardo Zandonini $^{\text {a }}$, Nadia Baldassino ${ }^{\text {a,* }}$, Fabio Freddi ${ }^{\text {b }}$, Giacomo Roverso ${ }^{\text {a }}$ \\ a Department of Civil, Environmental and Mechanical Engineering, University of Trento, Trento, Italy \\ ${ }^{\mathrm{b}}$ Department of Civil, Environmental and Geomatic Engineering, University College of London, London, UK
}

\section{A R T I C L E I N F O}

\section{Article history:}

Received 16 November 2018

Received in revised form 25 February 2019

Available online xxxx

\section{Keywords:}

Robustness

Progressive collapse

Steel-concrete composite frames

3D full-scale test

Slab-beam-systems

Semi-rigid joints

\begin{abstract}
A B S T R A C T
Accidental events, such as impact loading or explosions, are rare events with a very low probability of occurrence. However, their effects often lead to very high human losses and economic consequences. An adequate design against these events should reduce the risk for the life of the occupancy, minimize the damage extension and enable a quick rebuilding and reuse. A structure fulfilling these requirements is 'robust'. Different strategies can be pursued for accidental events, and among them, methods based on the residual strength or the alternate load path are frequently adopted because applicable to a vast range of structures. Adequate design strategies based on them require an in-deep knowledge of load transfer mechanisms from the damaged to the undamaged part of the structure. As to the frames, the important role of joint ductility was pointed out in recent studies. Besides, the flooring systems substantially affect the spread of the damage, but the research on this subject is still very limited. The present study focuses on steel-concrete composite frames under the column loss scenario. It aims to better understand the influence of both frame continuity and floor systems in the development of 3D membrane action. Two geometrically different 3D steel-concrete composite full-scale substructures were extracted from reference buildings and tested simulating the column collapse scenario. This paper illustrates the preparatory studies, the main features of the specimens and the outcomes of the first test. The test provided an insight in the need for an enhanced design of joints and pointed out the key features of the response of the floor system.
\end{abstract}

\section{Introduction}

Several catastrophic events increased the interest into the study of the effects of extreme loading onto the structural response [1]. A rational and well recognized design strategy [2-7] is to provide the structure with the ability to withstand events such as fire, explosions, impact and consequences of human error without being damaged to an extent disproportionate to the original cause. Fulfilment of this requirement identifies a 'robust' structural system.

Various research studies focused on the robustness since $1968[8,9]$ and allowed to build up an understanding of a robust structural response and to define possible design strategies that nowadays are incorporated in design specifications and codes. The accidental removal of columns is a typical design scenario to be adopted when checking the robustness. Columns' collapse triggers dynamic effects, large deformations of the floor system and high deformation of the beam-to-column joints. The extension of the associated damage strongly depends on the capability to redistribute loads from the damaged to the undamaged parts and to reach a new stable equilibrium configuration. In this

\footnotetext{
* Corresponding author.

E-mail address: nadia.baldassino@unitn.it (N. Baldassino).
}

context, the ductility of the joints and the 3D performance capabilities of the floor system are essential factors for a robust structural response.

Despite this general interest, only little research was carried out on steel and steel-concrete composite structures. Hence, no specific rules are available allowing the exploitation of their potential, in terms of limiting the extent of damages, due to their high bearing capacity and significant ductility. Research mainly focused on single members under impact loading. Few studies only accounted for the influence of the surrounding structure. Researchers investigated the structural robustness of composite frame systems under the column loss scenario. Kuhlmann et al. [10], within a European research project, focused on the definition of general ductility requirements of joints of a steel-concrete composite frame subjected to exceptional loading. As part of the same project, Demonceau and Jaspart [11] experimentally tested a 2D steel-concrete composite frame with partial strength joints under the central column removal scenario. The test confirmed the important role of ductile joints in the development of catenary action in the beams. Experimental studies [12-20] of the performance of different types of steel and composite connections recently investigated the axial force-bending moment interaction, and the associated failure modes and ductility. The tests proved that flush-endplate and web cleat connections exhibit good resistance with large rotation capacity in the tensile catenary range. 

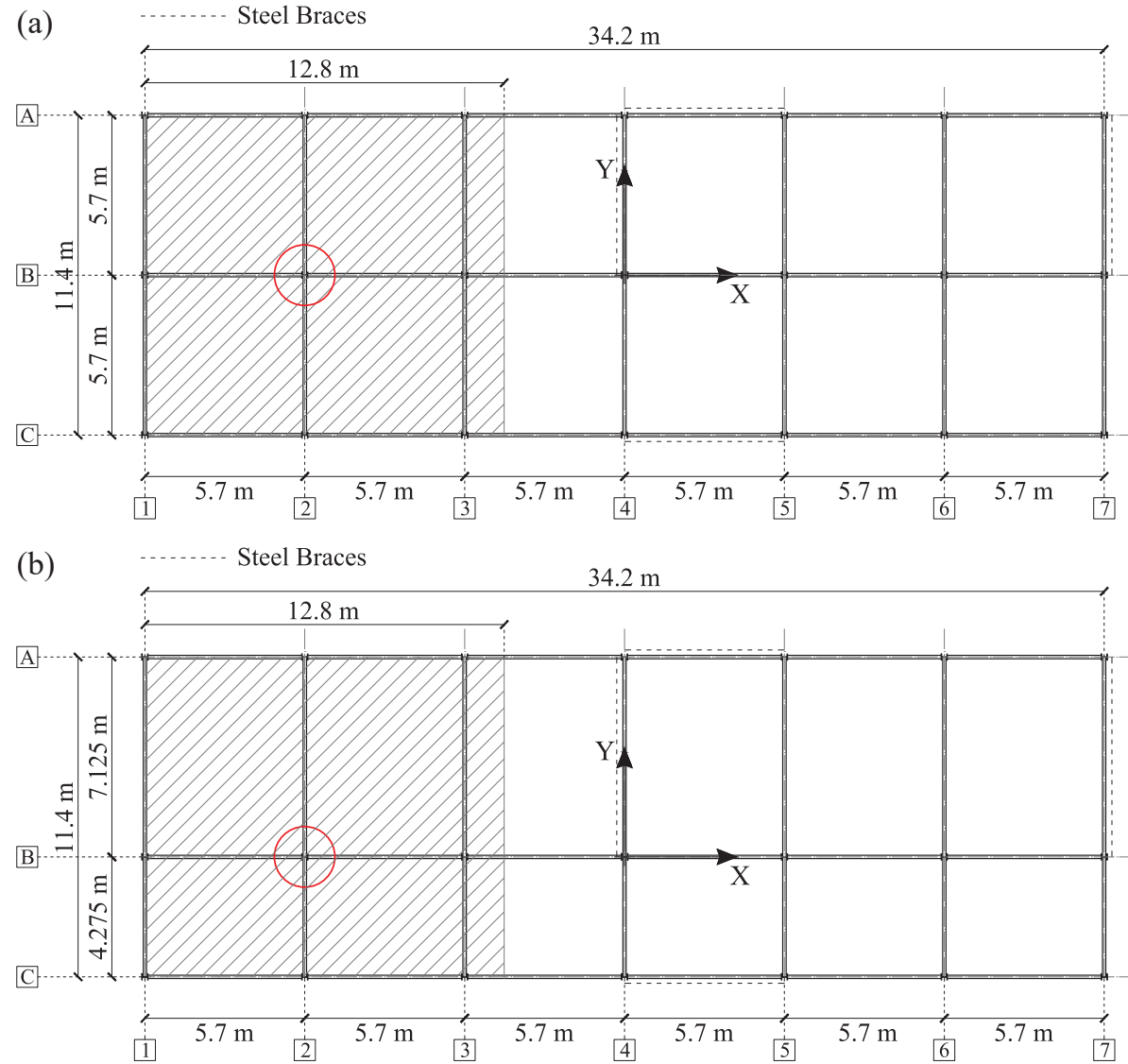

Fig. 1. Plan views of the reference structures.

Their tensile capacity usually is the main parameter that determines the failure of the system. Further tests on composite joints revealed a significant contribution to the load-carrying capacity of the joints during both the flexural and tensile catenary stages. Wang et al. [21] performed an experimental and computational study of two composite subassemblies under a column loss scenario aiming to have an insight into the slab effect, which was confirmed to be substantial. Studies focusing on the characterisation of 2D frames [22-25] singled out the different phases of their response under column removal: elastic, elastic-plastic, arching, plastic and catenary stages. The catenary action can increase significantly the load capacity of the frames, and the ultimate resistance is always governed by the rupture of the beam-to-column connections. All these studies investigated the 2D structural behaviour, while the 3D nature of the frame response was neglected. Dinu et al. [26] experimentally investigated the capacity of a 3D steel frame structure to support the loss of a central column and the capability of the frame to develop catenary action in the beams. A scaled-down specimen with two bays and two spans was extracted from a six-story steel moment-frame building. The slab was not considered in this study. The results showed a very good behaviour of the beam-to-column connections, which resisted the catenary forces developed in the beams. Foster et al. [27] carried out 15 small-scale tests on isolated horizontally unrestrained concrete slabs subjected to large vertical displacements. All the tested slabs showed a loadcarrying capacity far higher than the design capacity, highlighting the importance of the tensile membrane action in generating alternative load paths. An insight into the potential slab role in preventing progressive collapse is provided by the work of Qian and Li $[28,29]$ and Ren et al. [30]. They carried out static and dynamic tests on RC beam-column-slab substructures under central and corner column collapse. Jahromi et al. [31] performed an interior column removal test on a full-scale two-bay by two-bay and one story composite prototype building. The structure was built up with a steel frame with simple connections and a concrete floor slab poured over corrugated steel decking. The building resisted loads up to 1.6 times the ASCE 7-10 [32] extreme event load combination. Johnson et al. [33] tested a half-scale three by three bays composite steel-concrete frame under four separate column removal scenarios. The specimens behave well although robustness was not considered in the design.

Besides the experimental campaigns, several researchers [34-38] developed finite element models enabling investigation of the structure's performance under the column loss scenario. The computational studies made possible a further insight into the critical behavioural issues associated with the joints and membrane action in the slab in the large vertical displacements range. Comparing results of static and dynamic finite element analysis, Li and El-Tawil [38] showed that the structural members should be designed to have the axial capacity of at least twice the static axial force of the member. Besides, they pointed out that the building may be more vulnerable to column removal in upper than in lower storeys. Amongst others, Sadek et al. [39], Alashker et al. [40], Main [41] and Jahromi et al. [42] used computational models to evaluate the robustness of concrete corrugated decksteel beam composite floor systems with shear tab connections. The effects of some important parameters such as deck thickness, steel reinforcement and numbers of bolts in the shear tab connections on the behaviour of the structural system were investigated.

Other studies [43-45] dealt with analytical methods for assessing the robustness of building structures. These methods have the advantage of simplicity and direct application in design practice, without conducting static or dynamic finite element 
(a)

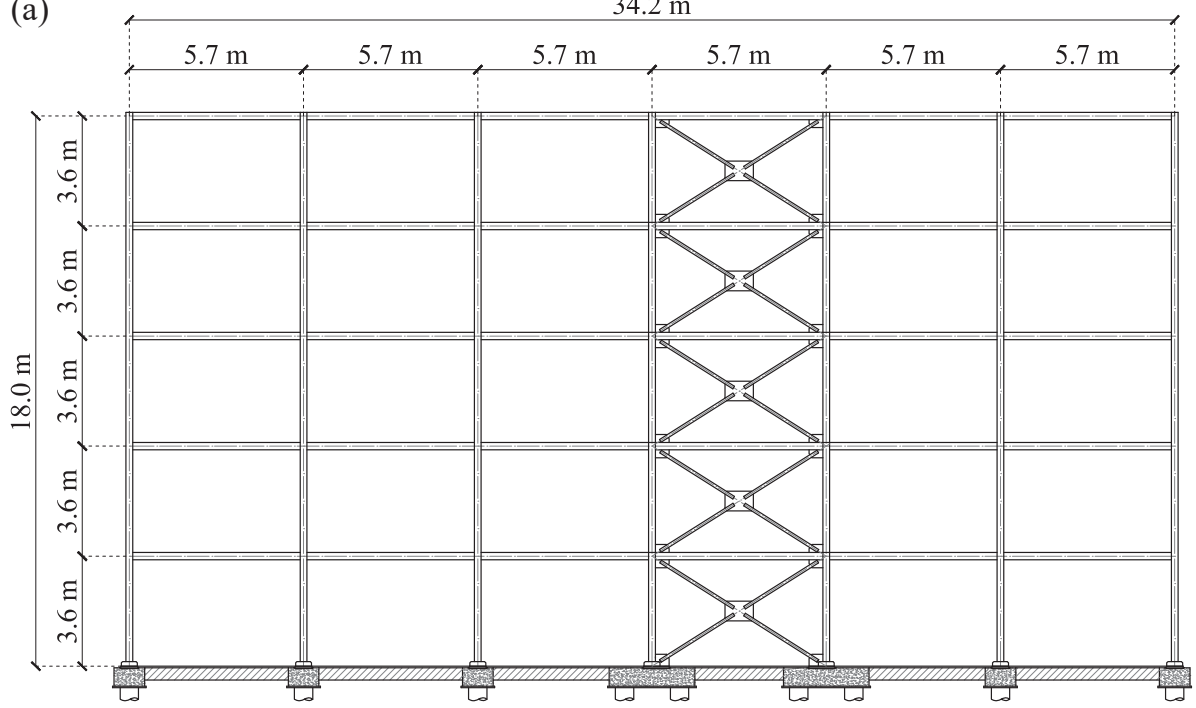

(b)

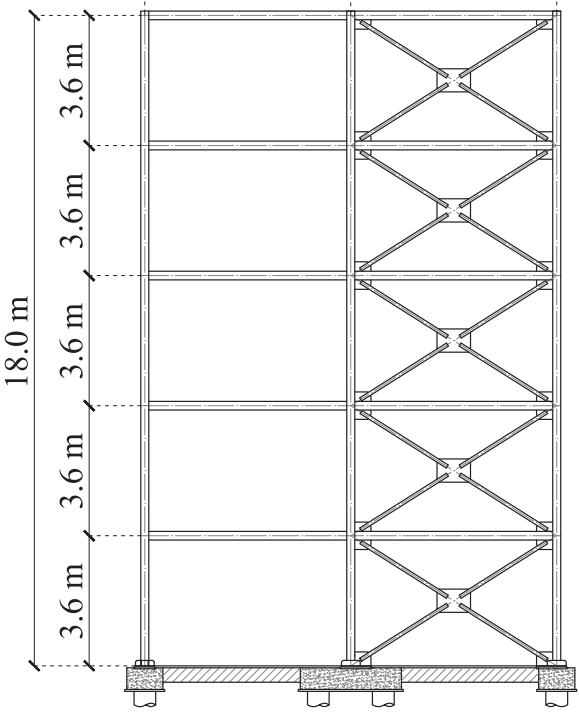

(c)

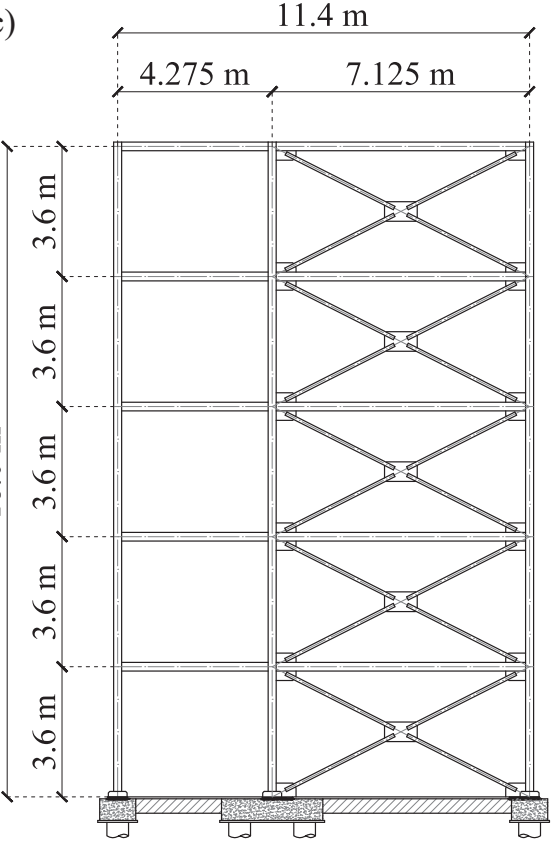

Fig. 2. Elevation views of the reference structures.

analysis. In particular, Izzuddin et al. [8] developed a multi-level simplified framework for progressive collapse assessment of multi-storey buildings considering a sudden column removal scenario, and Stylianidis et al. [46] proposed an analytical method for modelling the response of axially restrained steel and steelconcrete composite beams following the column loss.

The current literature focuses mainly on the 2D behaviour of composite frames or on the isolated behaviour of the slab by itself. In order to improve the knowledge of the actual frame response, full scale experimental tests on 3D frames are the most complete and recommended approach. Such experiments are expensive and complex, and limited experimental data are hence available.

Recently, a European RFCS Research Project entitled "Robust impact design of steel and composite building structures" [47] aimed at developing new design concepts for steel and concrete composite frames against accidental actions. The study concentrates on the different aspects of the performance of composite frames, made of steel skeleton, composite beams and solid concrete slabs. The study included a large number of static and dynamic tests on individual members and substructures. Two full-scale 3D steel and concrete composite sub-frames with solid slab and endplate beam-to-column connections were tested at the University of Trento, simulating the total loss of a central column. The experiments enabled investigation of the alternate load paths provided by the structural redundancy and the floor system in terms of activation of different resistance mechanisms. Equivalence between the sub-frames and the full-frames required a series of preliminary numerical analyses, in order to enable the definition of the boundary restraints of the specimens and of the loading sequence. The present paper illustrates the design of the specimens, the preparatory studies and the main experimental results of the first test. The importance of the concrete slab and of the beam-to-column joints in order to enhance the structural response is illustrated and discussed. 

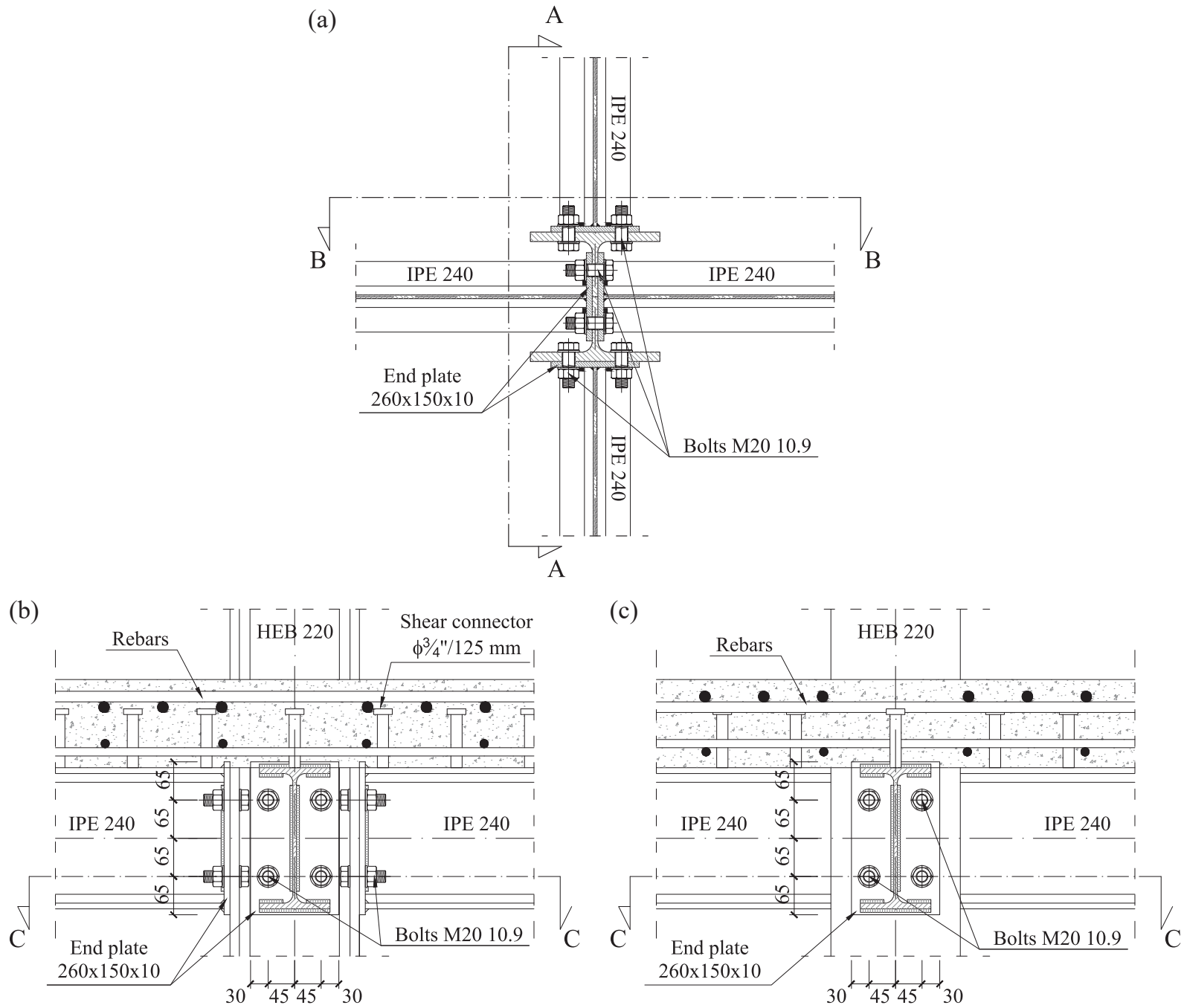

Fig. 3. Beam-to-column connections.

(a)

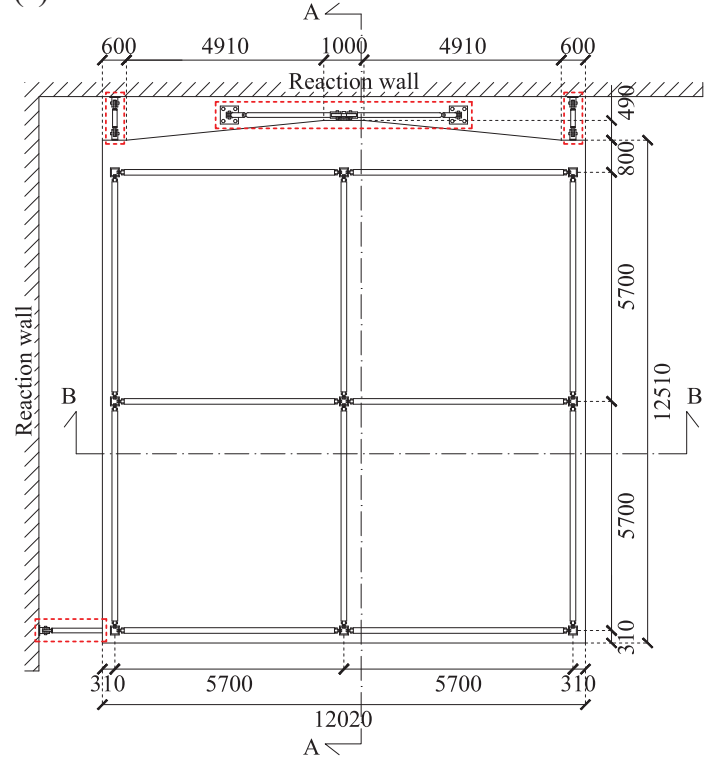

(b)
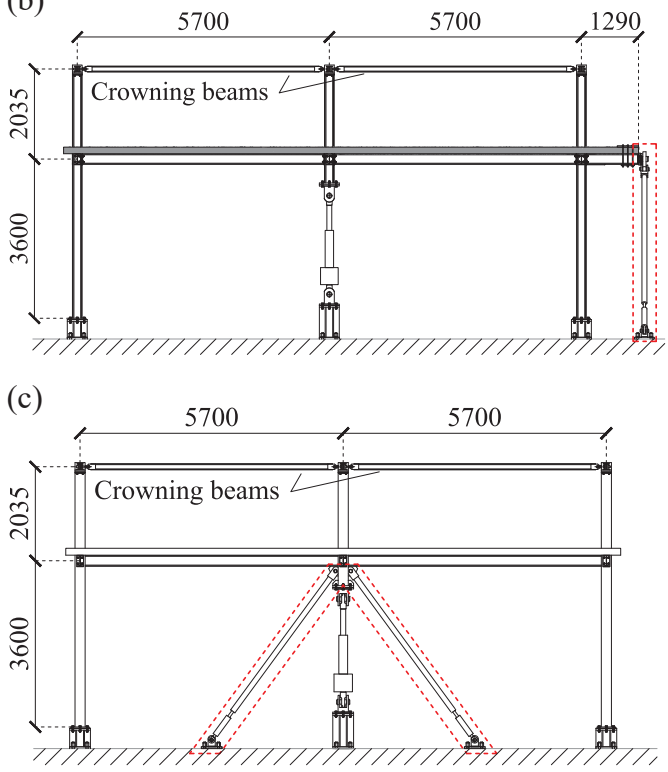

Fig. 4. Actual dimensions of the sub-frames (measures in $\mathrm{mm}$ ). 
Option 1

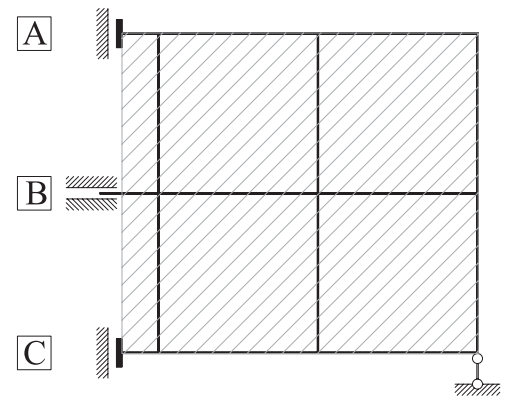

A

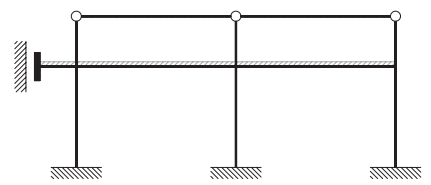

B

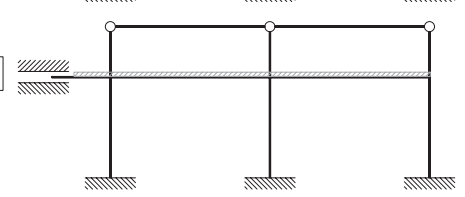

Option 2

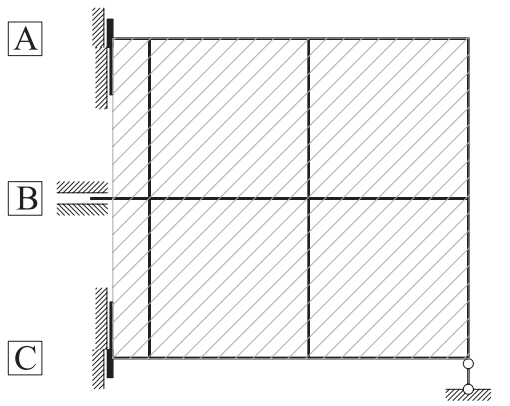

A
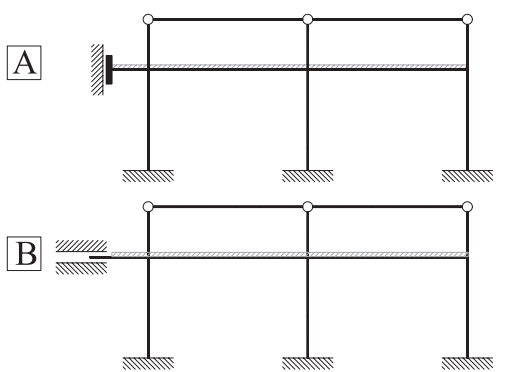

Option 3

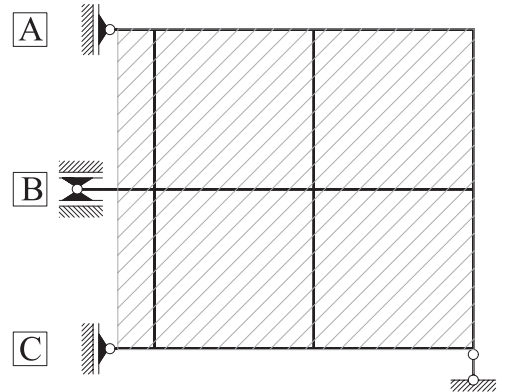

A

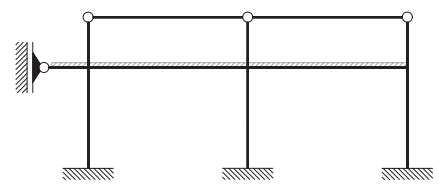

$\mathrm{B}$

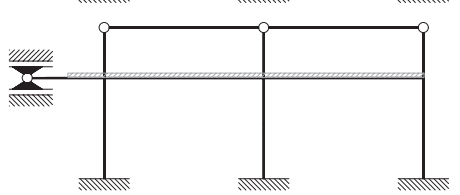

Fig. 5. Restraining options for the sub-frame - symmetric configuration.

\section{The case study frames}

In order to investigate real cases representative of popular solutions, the RFCS project [47] selected as case studies two five-storey composite steel and concrete office buildings. All experimental work was associated with these two frames. In particular, the sub-frames tested by the Authors were 'extracted' from these reference frames. This section concentrates on the design of the case study frames.

Two different geometric configurations of the frame were considered: the first configuration is symmetric with respect to both the plan directions, while the second one is symmetric only with respect to one plan direction. The two structures will be referred to hereinafter as 'Symmetric' and 'Asymmetric', respectively. The total dimension of the buildings are $34.2 \mathrm{~m}$ in the $\mathrm{X}$ direction (six bays) and $11.4 \mathrm{~m}$ in the $\mathrm{Y}$ direction (two bays), while the total height is $18.0 \mathrm{~m}$. Figs. 1 and 2 illustrates the plan and front views of the reference structures.

In Fig. 1, the shaded areas identify the substructures for the current study, and the red circles the column, whose loss was simulated. The position of steel braces designed to resist the horizontal actions in the Y direction is asymmetric in both the frames (see Fig. 1). This solution, despite less effective with respect to the seismic performance, has been adopted in order to avoid the presence of the steel braces in the sub-structures to be experimentally investigated. This makes the substructures more representative of a general case.

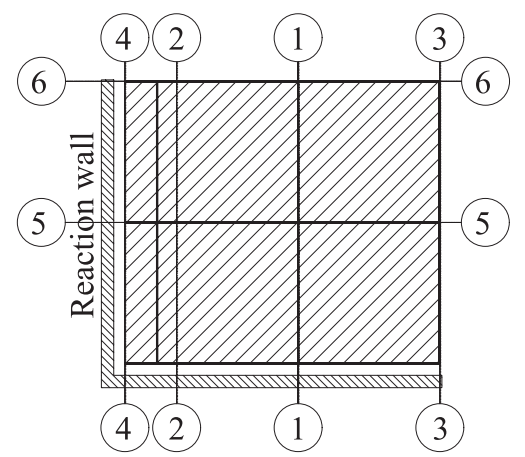

Fig. 6. Significant sections - symmetric configuration.
The design was based on the Eurocodes rules [48-52], and no seismic considerations were made in order to decouple the issues of seismic and robust design. Structural design aimed at getting for both structures the same sections of the steel members: i.e. HEB220 for the columns and IPE240 for the beams. In both structures, the thickness of the concrete slab is taken as $150 \mathrm{~mm}$, and the beam-to-column joints (Fig. 3) are bolted flush-endplates designed according to the component method as in the Eurocodes [48].

This criterion was chosen in order to reduce the number of variables and simplify the comparison of the results for the two structures.

The rebars layout in the concrete slab is hence the only nominal difference between the two frames. The rebars cover in the concrete slab is of $20 \mathrm{~mm}$. A welded wire mesh of $\phi 10 / 150 \times 150 \mathrm{~mm}$ is located at the top and bottom side of the slab, while $\phi 10$ and $\phi 16$ additional rebars in several zones at the internal and external beams. Full shear connection between steel beams and concrete slab is assumed. Structural steel grade S355, rebars grade B450C, bolts class 10.9 and concrete C30/37 are the materials selected for the structural elements. All details about the design of the reference structures can be found in [53].

The Finite Element Models of the 3D frames used for the design were developed by using the SAP 2000 environment [54]. The frames are fixed at the base in both the directions and employ elastic 2D elements 'Frame' to model beams, columns, and steel braces. The elastic 'Shell' element is used to model the slab. The contribution of the composite action is considered in the analysis by rigidly connecting the slab to the steel beams in order to simulate the complete interaction provided by the shear studs. The beam-to-column joints are modelled considering the rotational stiffness based on the component method of the Eurocodes. The global initial sway imperfection has been accounted for directly in the model, while the effect of bow imperfections has been considered when checking the individual structural elements. The creep and shrinkage of concrete has been considered in the design by using the appropriate modulus of elasticity of the concrete depending on the design situation in agreement with EN1994-1-1 [52,53].

\section{The full-scale tests}

The tests were performed on full-scale sub-frames extracted from the reference buildings. The goal was to investigate the frame performance under the column removal loading condition. 

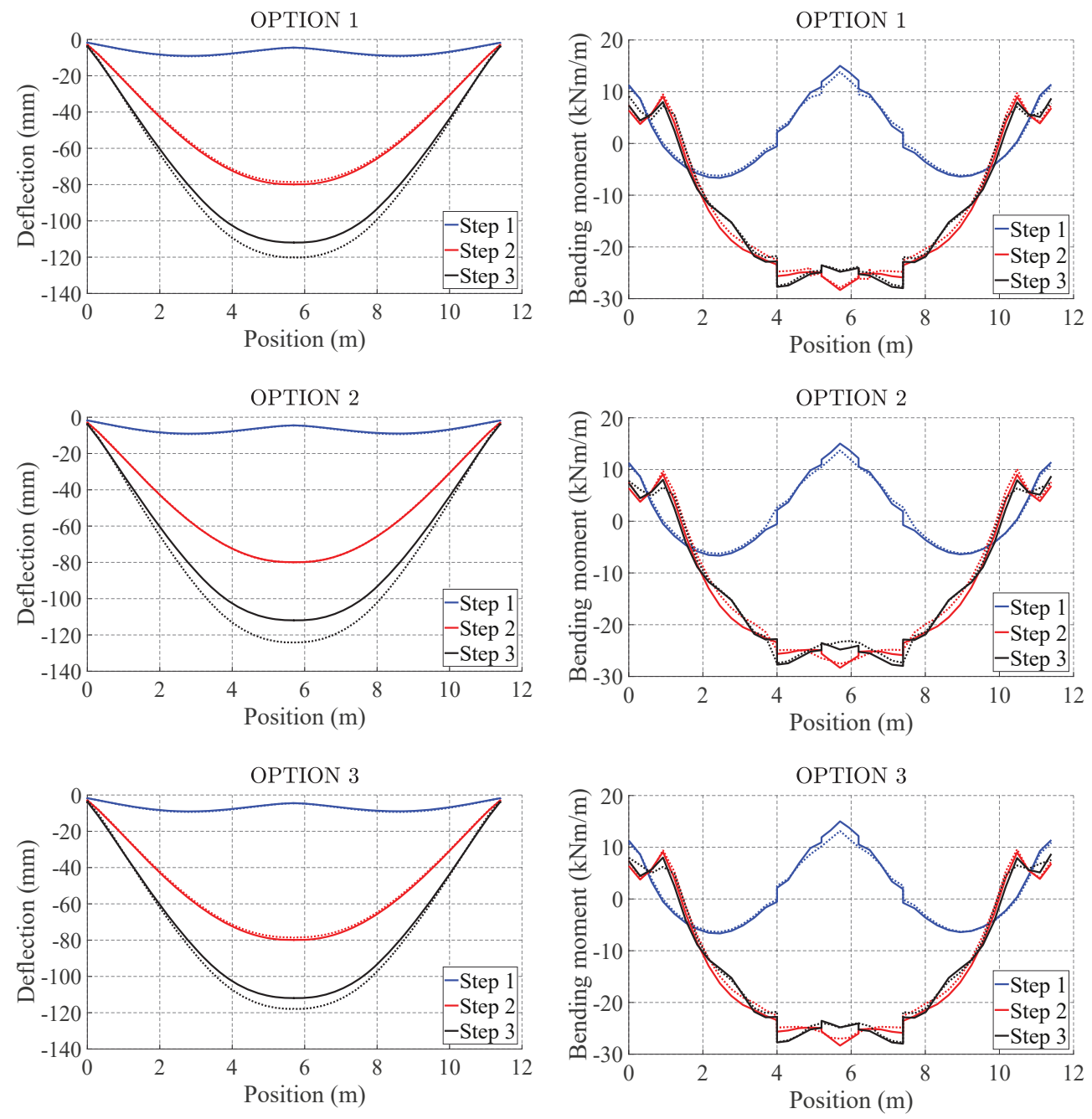

Fig. 7. Comparison of the vertical displacements and bending moments in the Section 1 - Symmetric configuration.

\subsection{The sub-frames}

The $2 \times 2$ bays sub-frames were 'extracted' from the first floor of the corresponding reference building, as illustrated by the shaded area in

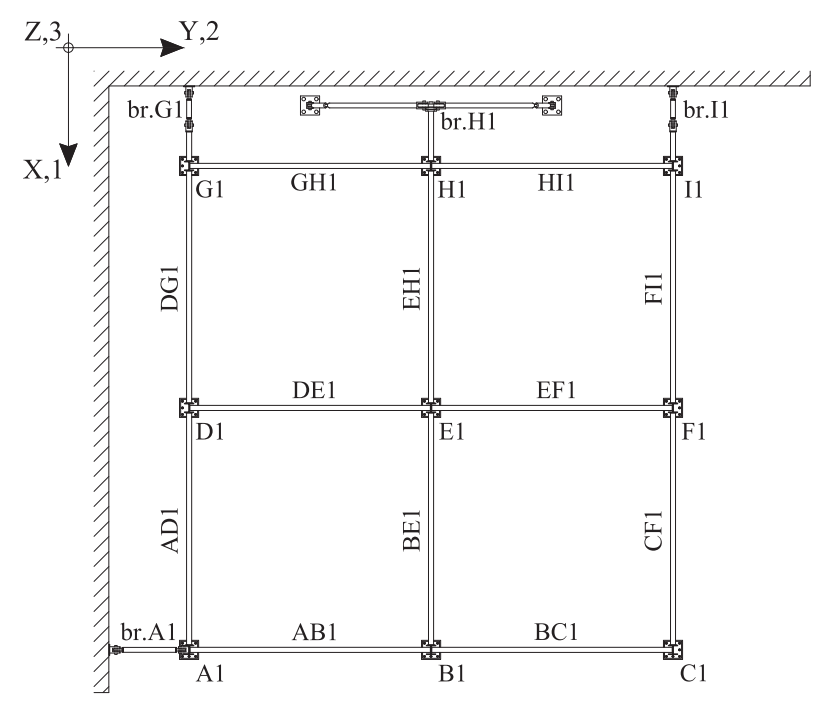

Fig. 8. Position of the lateral restraints - symmetric configuration.
Fig. 1. The red circle highlights the column that was removed during the test. More details about the sub-frames can be found in $[53,55]$. The plan view and plane sections of the 'Symmetric' sub-frame are illustrated in Fig. 4. In the figure, the dotted red lines mark off the lateral restraining system, which was studied and designed in order to minimize the behavioural difference between the full-frames and the subframes. The study also pointed out the need of extending the columns

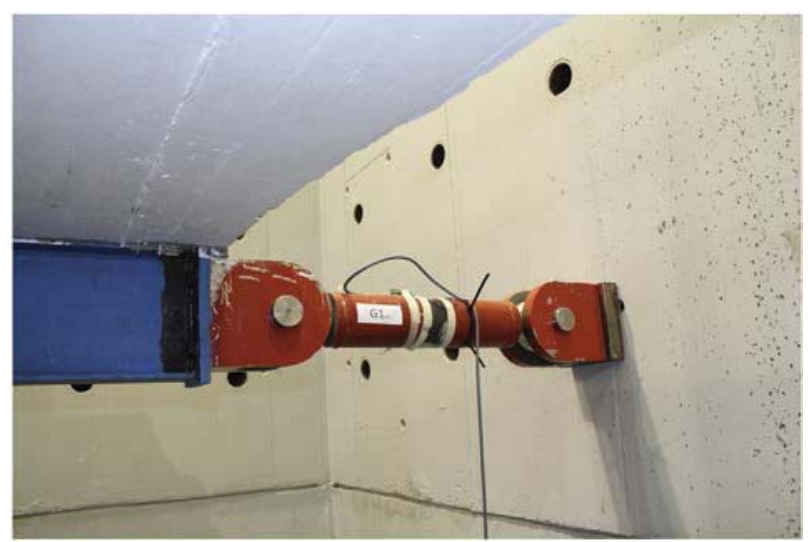

Fig. 9. The lateral restraint br.G1. 
beyond the first floor, and of connecting them by means of truss members (the crowning beams in Fig. 4).

\subsection{The restraining system of the sub-frames}

\subsubsection{Selecting the type of restraining system}

Finite element analysis of the full-frames and of the sub-frames [56] provided the background to the design of the experimental tests and, in particular, of the lateral restraining system that connects the specimens to the strong floor and to the counter-walls of the laboratory. The goal of the analysis was to mimic in the test the presence of the bracing system and of the remaining part of the reference structure. Three different restraining options, as illustrated in Fig. 5, were considered in the analysis, and the main results of the sub-frames analysis in terms of deformations and internal forces were compared with the corresponding ones obtained for the full-frames. In particular, the adequacy of the boundary restraining system is checked by comparing the response of the structure at several significant sections as reported in Fig. 6. In this paper, only the results related to Section 1 for the Symmetric frame are reported.

In the Option 1 and 3, only the steel beams are restrained with the counter-walls, while the slab is not connected to it. Both the options consider that the presence of the bracings in full-frames prevents from any significant longitudinal displacement: i.e., the relevant d.o.f. U1 is fully restrained at the lateral beams A and C (Fig. 5), while is left free at the central frame B. Besides, in Option 1 the vertical and lateral displacements (U2 and U3) of the central beam B and the rotation R2 and $\mathrm{R} 3$ at the end of the beams $\mathrm{A}$ and $\mathrm{C}$ are restrained.

In Option 2, in addition to the restraints of Option 1, also the part of the slab adjacent to the lateral beams are connected to the counterwall for a width of $0.5 \mathrm{~m}$, restraining all the translational degrees of freedom. The Option 3 is similar to the Option 1, but all the rotations are released.

Fig. 7 compares the vertical displacements and bending moments of the slab along Section 1 for the three different restraining options. The dotted lines relate to the sub-frame, while the continuous line to the full-frame. The responses are reported for three steps of the numerical analysis. In particular, in Step 1 the gravity load is applied on the slab, in Step 2 the central column is completely removed, and in Step 3 the load on the slab is increased by $30 \%$. From the analysis of the Fig. 7 , the results of the three options are very similar between them. Moreover, it is possible to observe that all of them are able to approximate more than satisfactorily the behaviour of the full-frame in terms of displacements and bending moments.
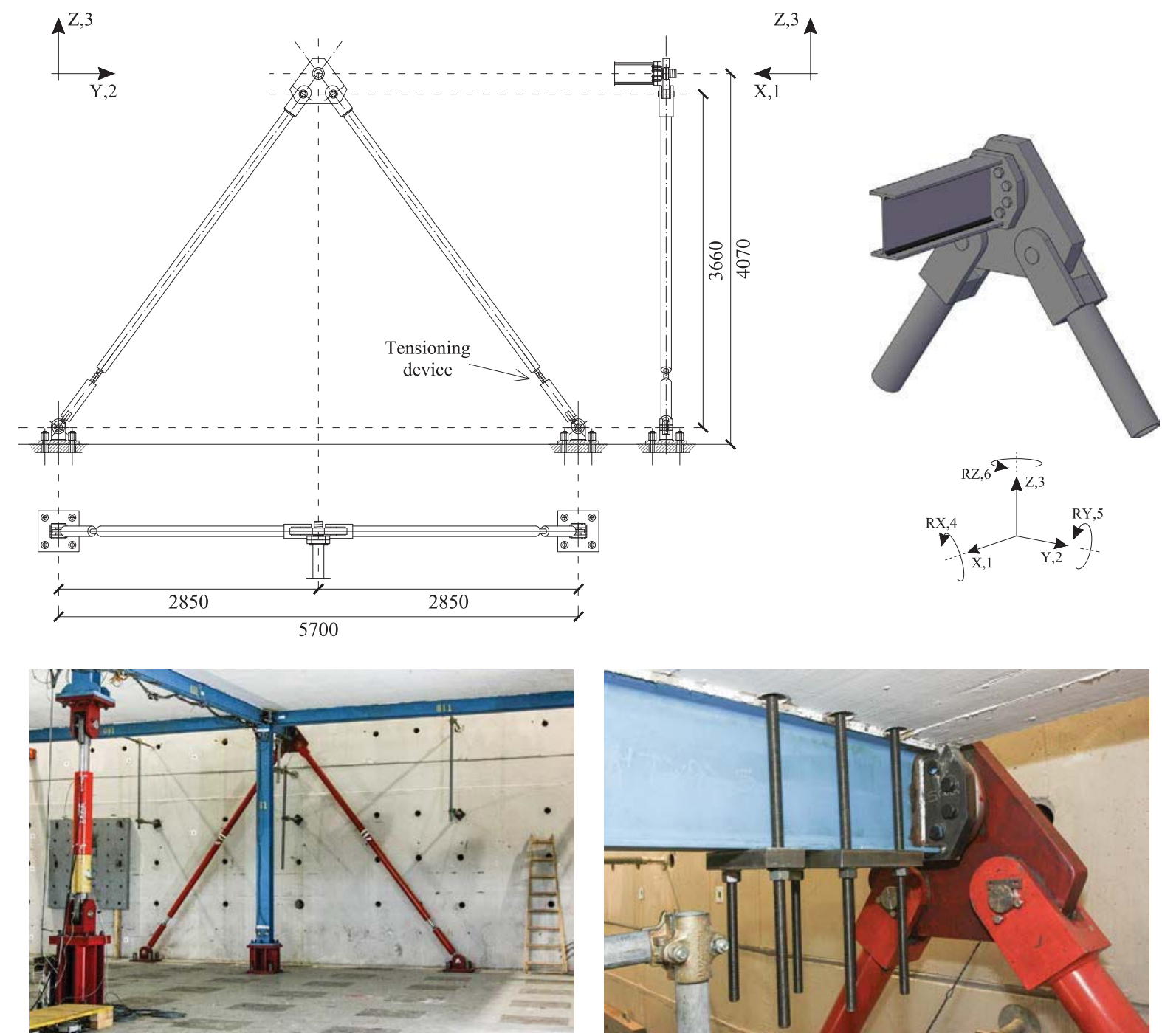

Fig. 10. The truss system br.H1 (measure in $\mathrm{mm}$ ). 
(a)

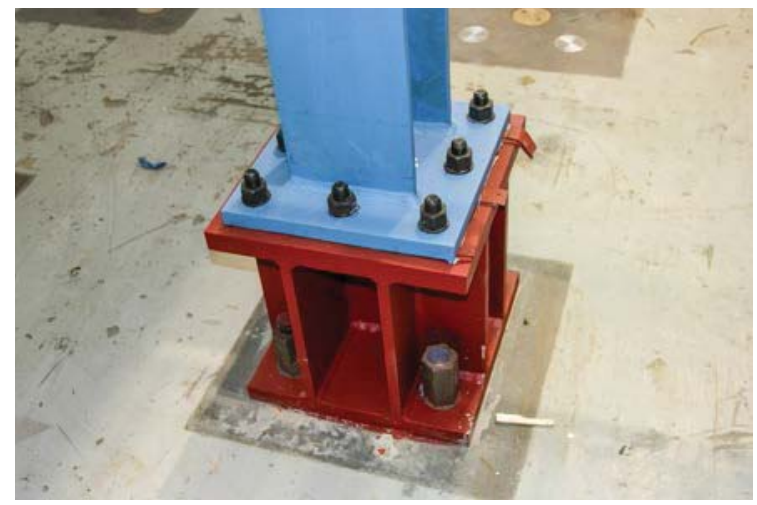

(c)

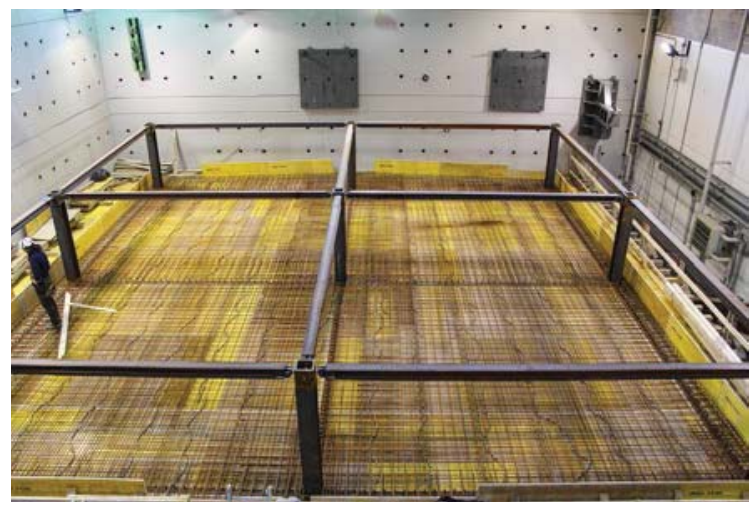

(b)

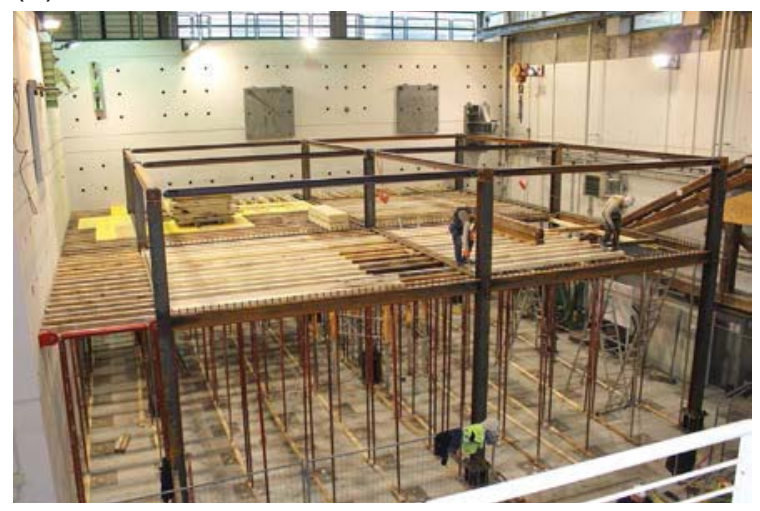

(d)

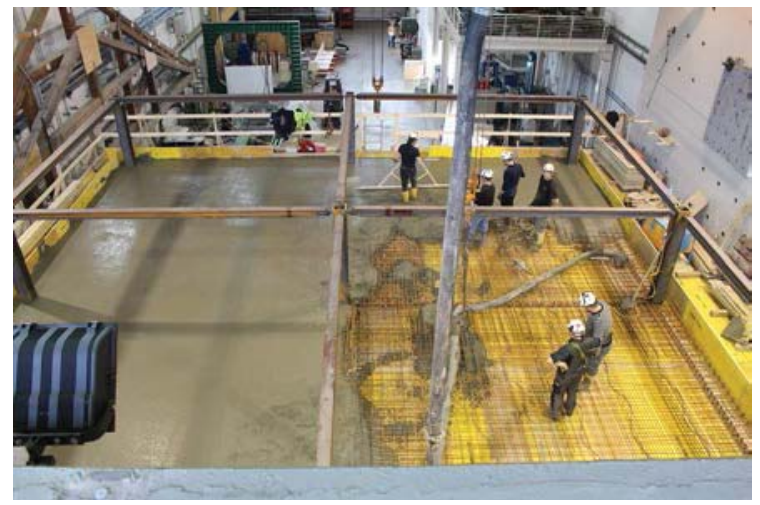

Fig. 11. The constructional phases.

The Option 3, where all the lateral restraints can be made up by steel truss elements connected to the steel frame, was hence selected for the restraining system.

As mentioned before, the analyses also pointed out the need for a system of crowning truss members pinned to the top end of the columns to take into account the influence of the upper stories present in the reference structure. The length of $2035 \mathrm{~mm}$ of the columns above the flooring system (Fig. 4) approximates the position of the contraflexure points in the second storey.

\subsubsection{The design of the restraining system}

In accordance with Option 3 (Fig. 5), the restraining system is made up of horizontal and vertical restraints connecting the steel frame to the

\section{(a)}

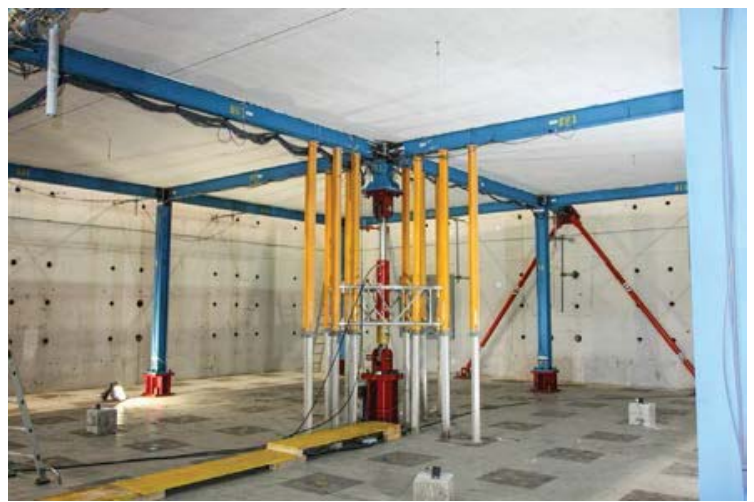

counter-walls and to the strong floor of the Laboratory. In particular, horizontal restraints are positioned in correspondence of columns A1, G1 and I1 and are named as br.A1, br.G1 and br.I1 respectively (Fig. 8). These restraints (illustrated in Fig. 9) prevent only the horizontal displacement in the Y direction (br.A1) and X direction (br.G1 and br.I1) respectively.

They are pin members connected at the ends by means of ball joints behaving as pins vertically and allowing 6 degrees of maximum rotation in the horizontal plane. In correspondence of the column $\mathrm{H} 1$ is installed a truss system (br.H1 in Fig. 10). This system prevents the displacements in $\mathrm{Y}$ and $\mathrm{Z}$ directions respectively and leaves free all the rotational d.o.f. (RX, RY and RZ) and the displacement in the X direction. The analyses of the restrained sub-frames enabled checking of the restraining

(b)

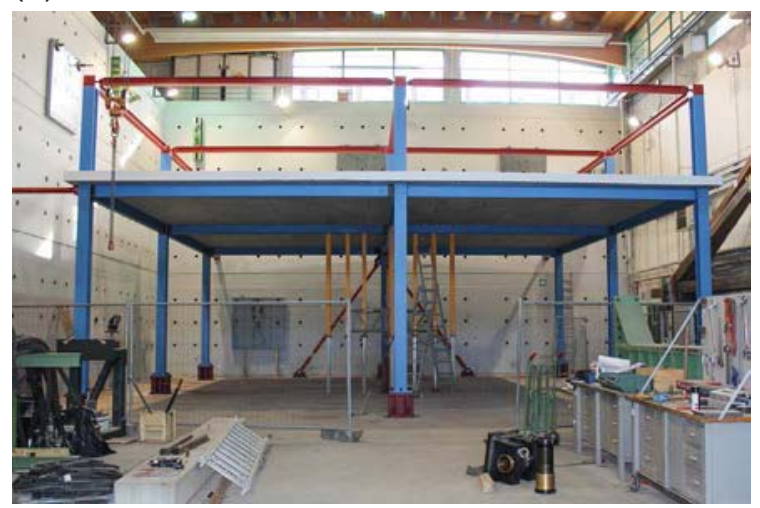

Fig. 12. The specimen at the end of the constructional phases. 
Table 1

Concrete properties.

\begin{tabular}{lllll}
\hline Type of test & $\begin{array}{l}\text { Concrete } \\
\text { age (days) }\end{array}$ & $\begin{array}{l}\text { No. of } \\
\text { tests }\end{array}$ & $\begin{array}{l}\text { Average cube } \\
\text { compressive strength } \\
\text { (MPa) }\end{array}$ & $\begin{array}{l}\text { Average tensile } \\
\text { splitting strength } \\
\text { (MPa) }\end{array}$ \\
\hline Compression tests & 7 & 3 & 43.83 & - \\
& 28 & 9 & 56.47 & - \\
Splitting tests & 102 & 6 & 65.74 & - \\
& 28 & 6 & - & 3.81 \\
& 102 & 9 & - & 4.25 \\
\hline
\end{tabular}

Table 2

Mechanical properties of the reinforcement bars.

\begin{tabular}{lll}
\hline Rebars diameter $(\mathrm{mm})$ & Yield stress $(\mathrm{MPa})$ & Ultimate tensile strength $(\mathrm{MPa})$ \\
\hline 10 & 496 & 586 \\
16 & 523 & 631
\end{tabular}

Table 3

Mechanical properties of the structural steel.

\begin{tabular}{clllll}
\hline Component & $\begin{array}{l}\text { Yield } \\
\text { stress } \\
(\mathrm{MPa})\end{array}$ & $\begin{array}{l}\text { Average } \\
\text { yield stress } \\
(\mathrm{MPa})\end{array}$ & $\begin{array}{l}\text { Ultimate } \\
\text { tensile } \\
\text { strength (MPa) }\end{array}$ & $\begin{array}{l}\text { Average } \\
\text { ultimate tensile } \\
\text { strength (MPa) }\end{array}$ & $\begin{array}{l}\text { Fracture } \\
\text { strain A } \\
(\%)\end{array}$ \\
\hline Column & 300 & 303.3 & 441 & 440.3 & 34.9 \\
HEB 220 & 306 & & 442 & & 34.5 \\
& 304 & & 439 & & 36.1 \\
Beam IPE & 383 & 409.3 & 537 & 540.7 & 28.2 \\
240 & 391 & & 541 & & 27.0 \\
& 454 & & 544 & & 33.3 \\
Endplate & 373 & 371.7 & 562 & 559.0 & 32.6 \\
10 mm X & 370 & & 560 & & 33.1 \\
dir & 372 & & 556 & 558.0 & 30.4 \\
Endplate & 382 & 381.3 & 558 & & 30.9 \\
10 mm Y & 380 & & 559 & & 26.0 \\
dir & 382 & & 557 & &
\end{tabular}

system as detailed. Technological issues and axial stiffness requirements lead to select steel circular hollow section $114.3 \times 6.3 \mathrm{~mm}$, steel grade S355 for all the members. The trusses of br.H1 incorporate pretensioning devices in their bottom part (Fig. 10).

\section{The experimental test on the symmetric structure}

\subsection{The construction of the specimen}

The specimen was built inside the Laboratory of Materials and Structures Testing of the University of Trento. The construction of the frame started with the erection of the steel skeleton connecting the columns with the strong floor of the laboratory (Fig. 11a) and the lateral bracings to the counter-walls. Bolts were tightened with a specific torque measured by a calibrated wrench, corresponding to $80 \%$ of the yield stress. Afterward, the formwork was put in place, the reinforcement positioned and the concrete poured in three casting phases (Fig. 11b, c, d respectively). Samples of concrete for the appraisal of the material properties were cast. The central column was 'replaced' by a hydraulic jack (Fig. 12a). During the constructional phases, the central beams were held in position by using a provisional propping system to be removed when the hydraulic jack was activated. The maximum capacity of the jack was of $1000 \mathrm{kN}$ in compression and of $400 \mathrm{kN}$ in tension. Fig. 12b illustrates the specimen at the end of construction. A check about the discrepancies between the design geometry and the real structure was then conducted. In particular, the average value measured for the slab thickness was of $165 \mathrm{~mm}, 15 \mathrm{~mm}$ higher than the design value of $150 \mathrm{~mm}$. Such a difference is mainly due to the complexity of the multi-layer rebars positioning in particular in the external joints area [53].

\subsection{Materials}

Material standard tests were performed and the results are here summarized.

\subsubsection{Concrete}

Compression and splitting tests on concrete samples were performed according to the recommendations of [57,58], respectively. During the casting phase, cubes and cylinders were taken from each of the three phases of the concreting. In particular, a total of 18 cubes (150 $\mathrm{mm}$ side) and 15 cylinders (150 $\mathrm{mm}$ diameter and $300 \mathrm{~mm}$ high) were prepared. In order to appraise the development of the concrete compression resistance, tests on cubes were performed at the age of 7 days, 28 days and 102 days (e.g. the time of the full-scale

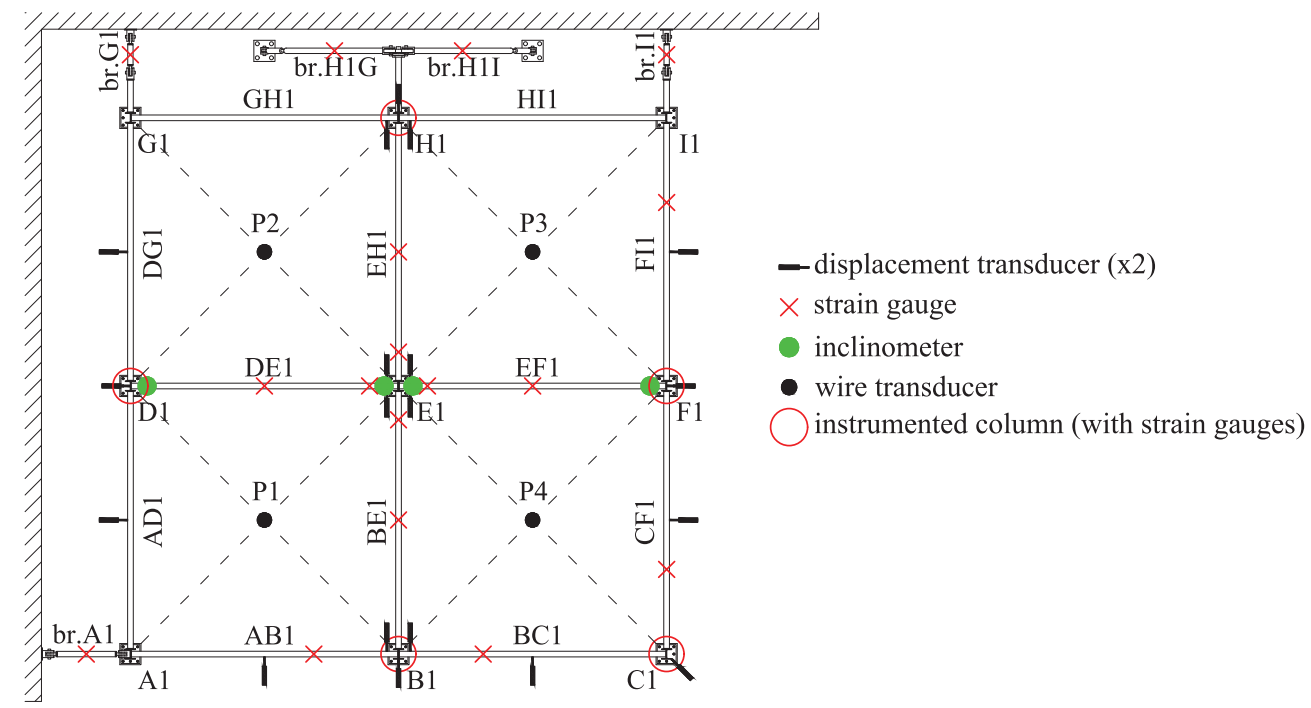

Fig. 13. The instrumentation set-up. 

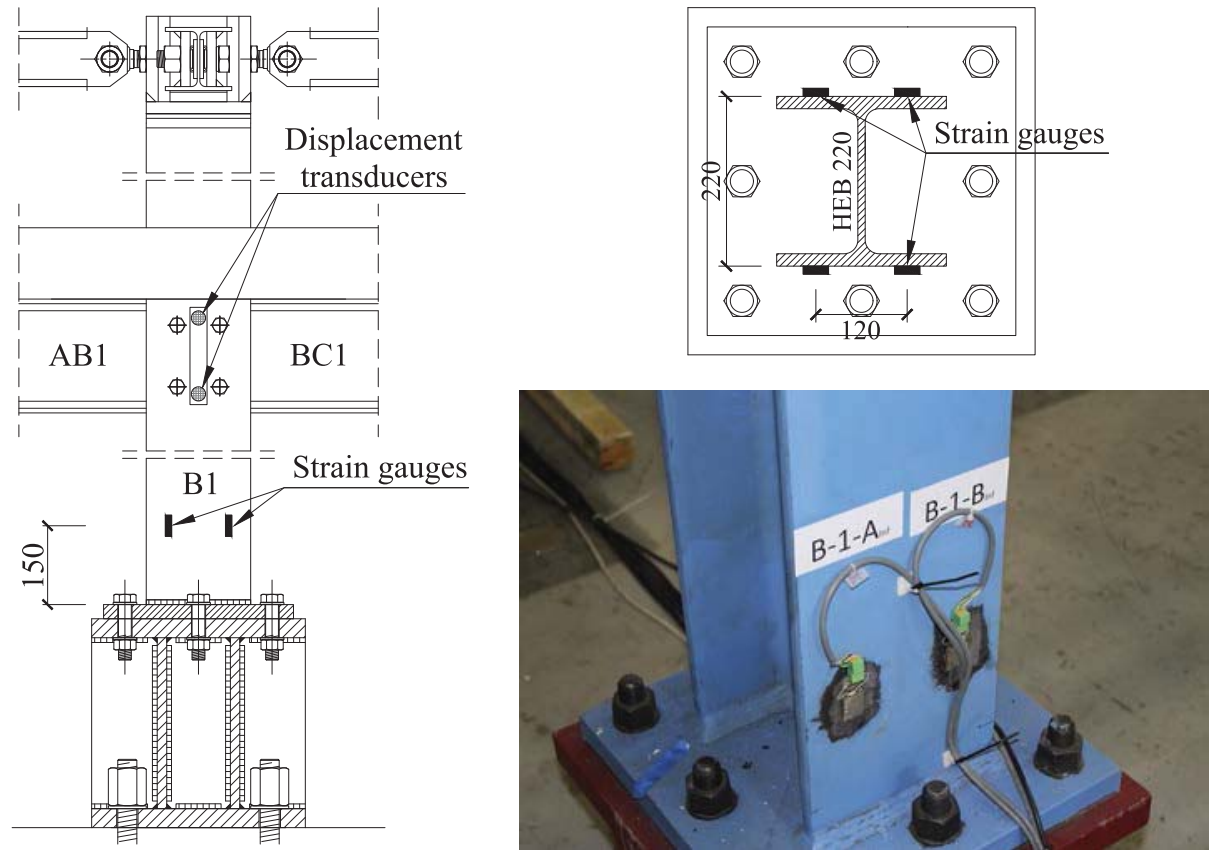

Fig. 14. Strain gauges at the columns base.

test) from casting. Splitting tests on cylinders were conducted at the age of 28 days and 102 days. The concrete properties are reported in Table 1.

\subsubsection{Steel}

Mechanical properties of the steel components obtained from tensile tests are summarized in the following. Table 2 reports the properties of the reinforcement bars, and Table 3 gathers those of the structural steels.

\subsection{The measurement set-up}

Due to the complexity of the frame response, the key parameters to be measured during the test were first identified. The specimen was then extensively instrumented to maximise the information gained from the experiment. The instrumentation set-up is illustrated in Fig. 13. The attention was focused on the response of the columns, beams, joints and the behaviour of the slab. In particular, strain gauges were installed to measure the strain state at the columns base (Fig. 14), at
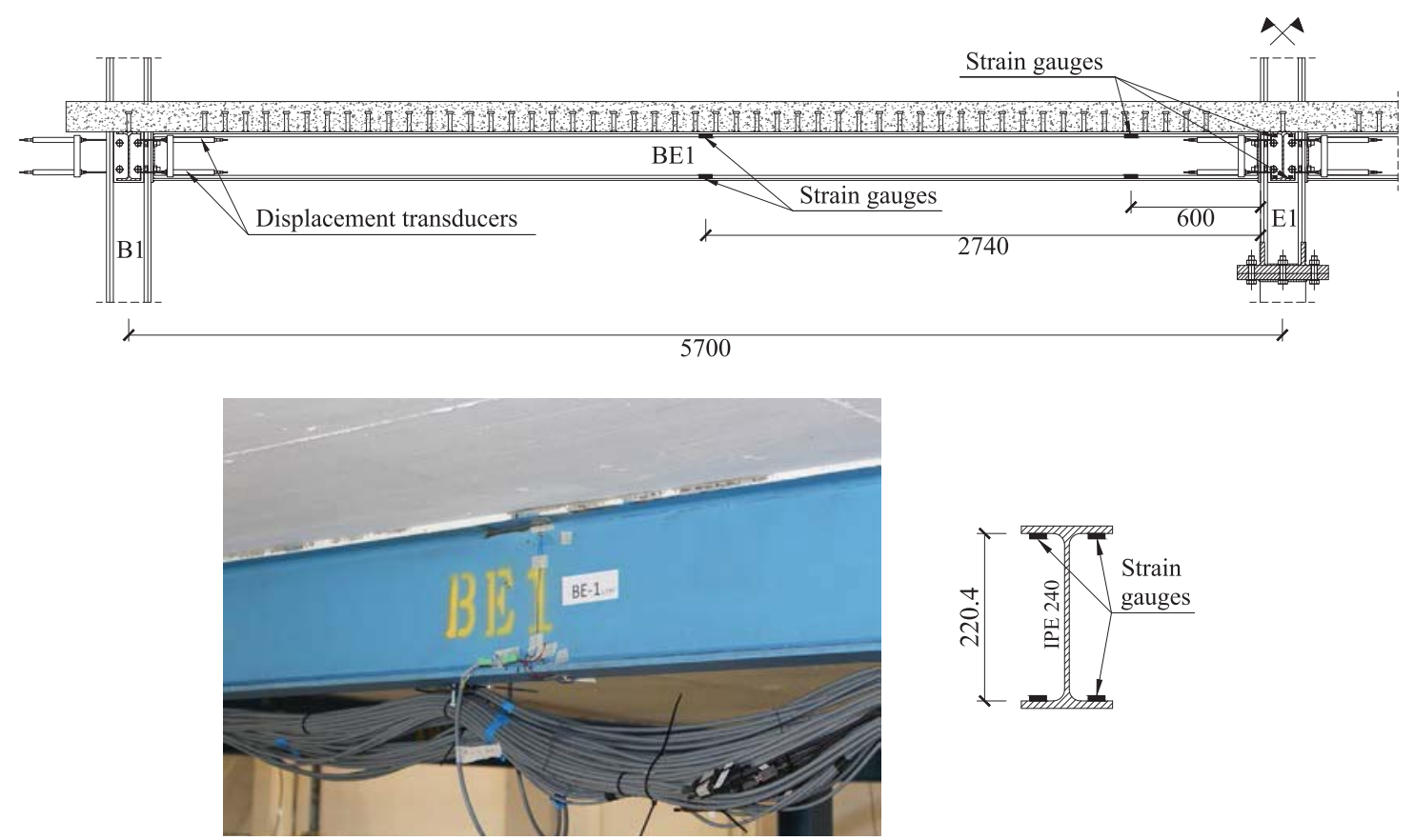

Fig. 15. Strain gauges in the internal beams. 


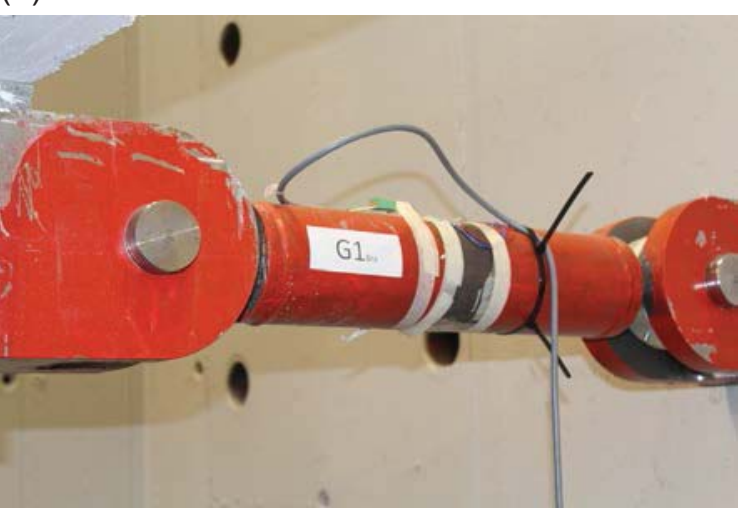

(b)

(a)

(c)

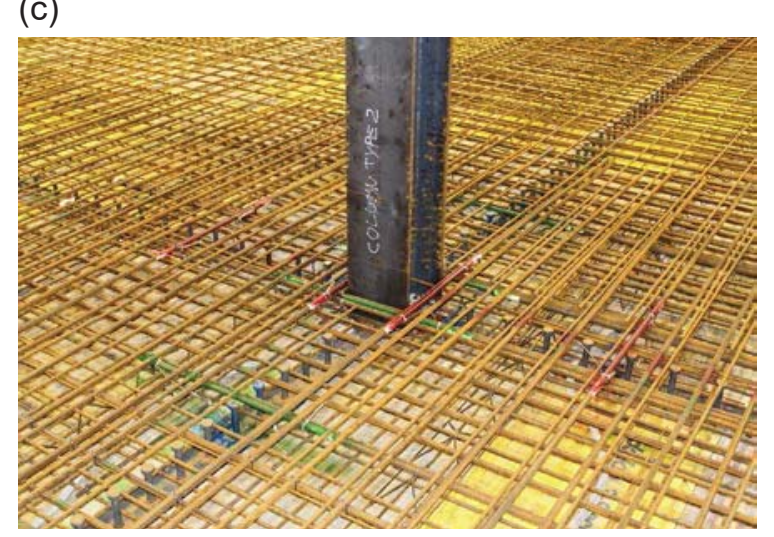

Fig. 16. Straing gauges in: (a) the lateral restraining elements, (b) the crowning beams, (c) the rebars.

(a)

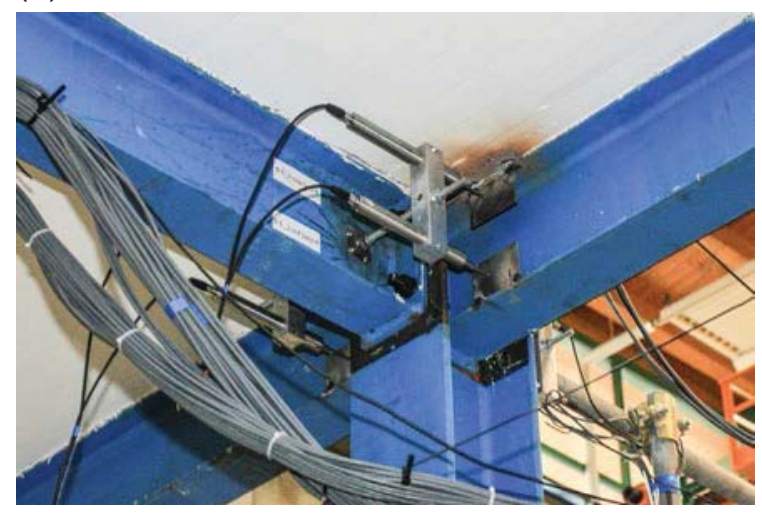

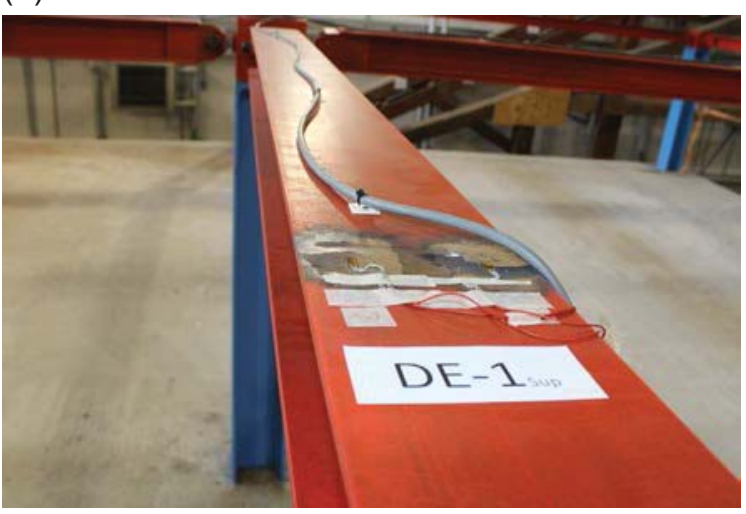


Table 4

Instruments installed and parameters measured.

\begin{tabular}{|c|c|c|c|}
\hline Structural element & Instrument & Parameter measured & Parameter deducted \\
\hline \multirow[t]{3}{*}{ Columns } & Strain gauges at the base & Average axial strain & Axial force \\
\hline & & Curvature (strong and weak axis) & Bending moment \\
\hline & LVDTs at the beam level & Rotation & - \\
\hline \multirow[t]{2}{*}{ Central beams } & Strain gauges at mid-span and near the central column & Average axial strain & Axial force \\
\hline & & Curvature (strong axis) & - \\
\hline \multirow[t]{2}{*}{ Lateral beams } & Strain gauges at mid-span & Axial strain & Axial force \\
\hline & LVDTs at mid-span & Torsional rotation & - \\
\hline Crowning beams & Strain gauges at mid-span & Axial strain & Axial force \\
\hline Lateral restraints & Strain gauges at mid-span & Axial strain & Axial force \\
\hline Reinforcement bars & Strain gauges near the central column & Axial strain & Axial force \\
\hline \multirow[t]{2}{*}{ Joints } & LVDTs & Rotation & - \\
\hline & Inclinometers & Rotation & - \\
\hline Slab panels & Wire transducer & Vertical displacement & - \\
\hline \multirow[t]{2}{*}{ Hydraulic jack } & Load cell & Axial load & - \\
\hline & Wire transducer & Vertical displacement & - \\
\hline
\end{tabular}

(a)

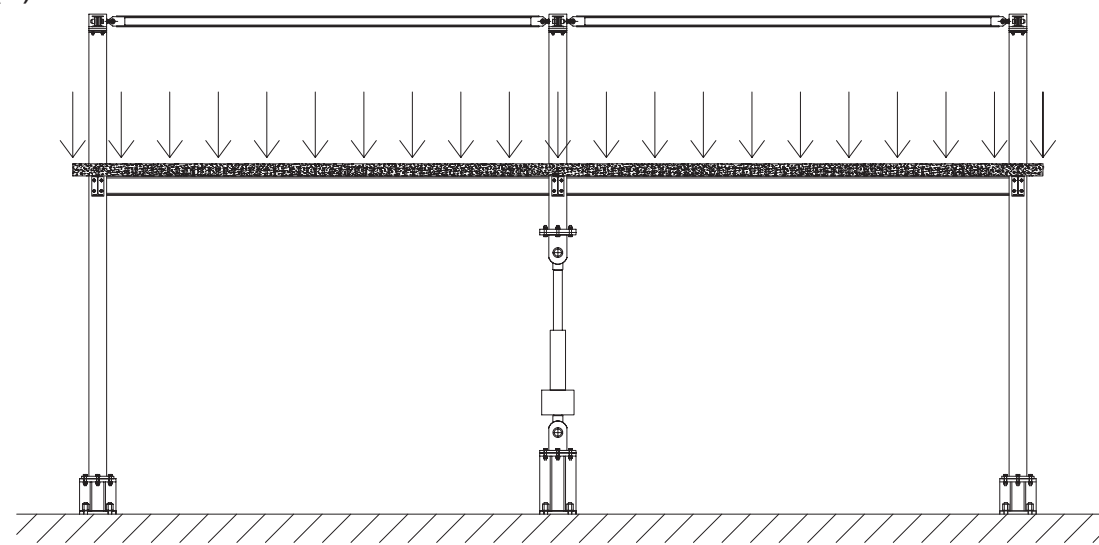

(b)

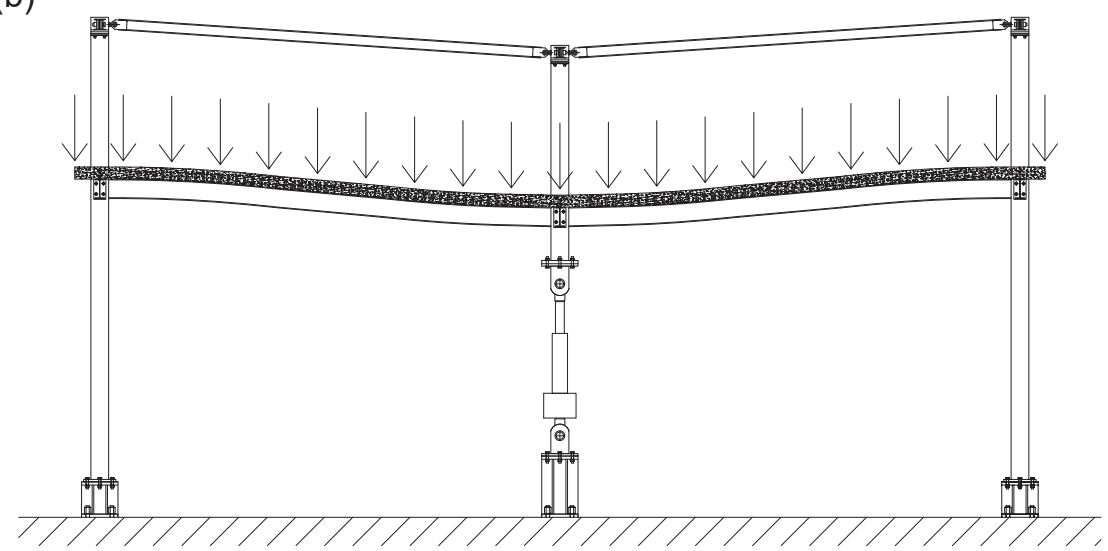

(c)

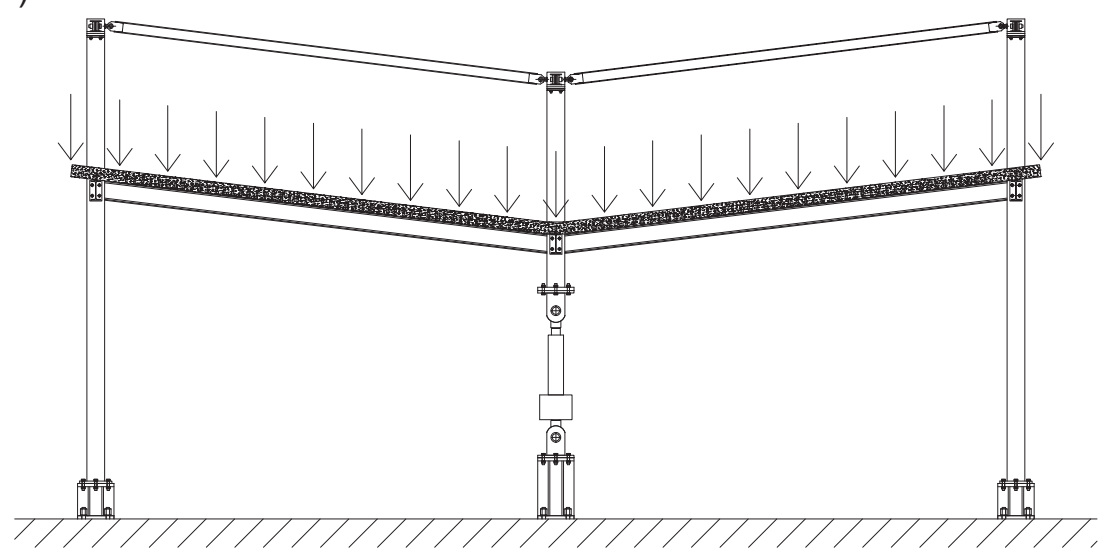

Fig. 19. The testing phases 
(a)

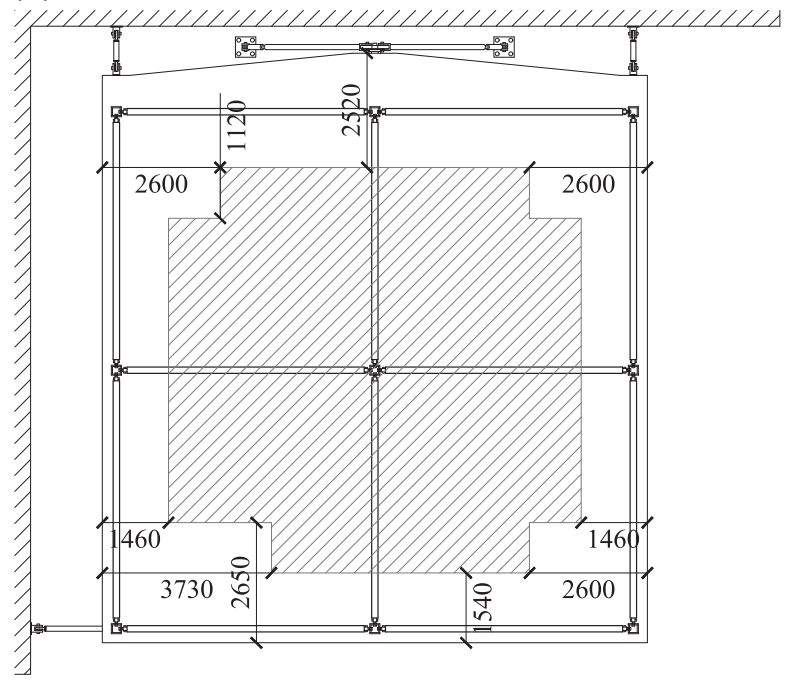

(b)

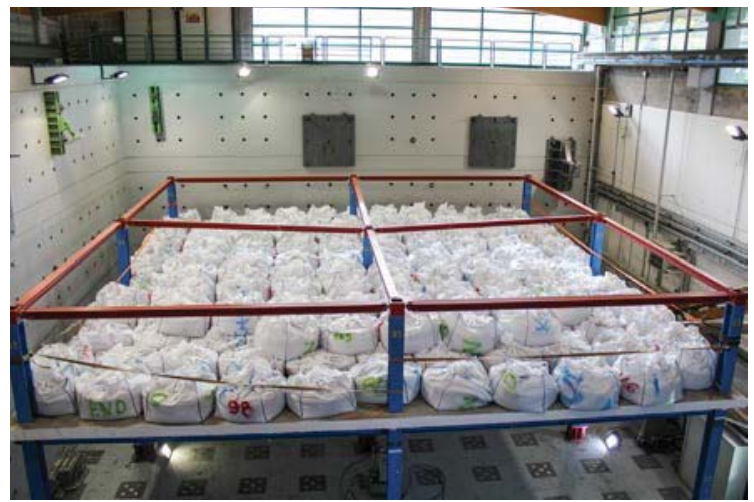

Fig. 20. Loading layout.

Table 5

Vertical load applied onto the slab.

\begin{tabular}{llll}
\hline & Total load $(\mathrm{kN})$ & Area $\left(\mathrm{m}^{2}\right)$ & Distributed load $\left(\mathrm{kN} / \mathrm{m}^{2}\right)$ \\
\hline 1st layer & 894.31 & 153.26 & 5.83 \\
2nd layer & 440.47 & 75.01 & 5.87 \\
\hline
\end{tabular}

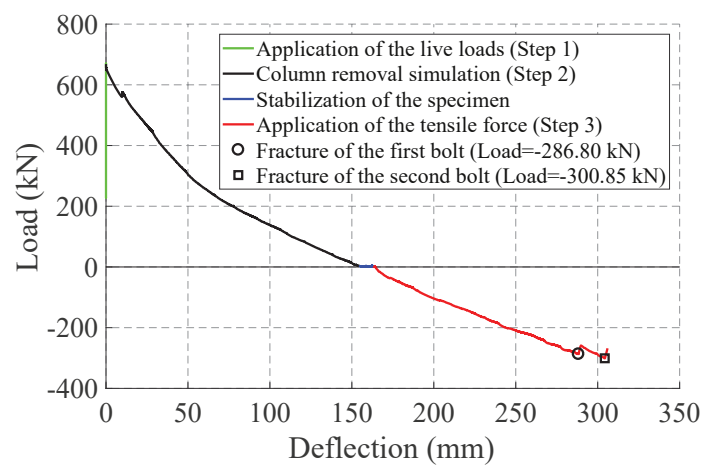

Fig. 21. Load-vertical displacement of the central column.

(a)

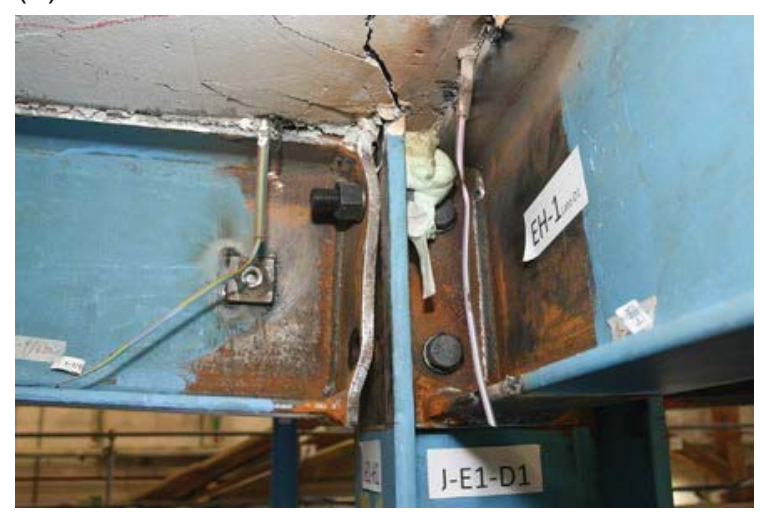

the mid-span and near the end connected to the 'central column' in the internal beams (Fig. 15), and close to mid-span of four external beams. The location of the strain gauges in the beams are identified by the red crosses in Fig. 13. The strain gauges readings enable determination of parameters such as the average axial strain and the curvature of the section. Under the assumption of the elastic material, these data allow to compute the axial force and the bending moments. Strain gauges to measure the axial strain were also installed in the lateral truss restraining elements, in the crowning beams and in several reinforcement bars in the top side of the slab and in correspondence of the central column (Fig. 16). Linear variable displacement transducers (LVDTs) and inclinometers were installed in correspondence of the beam-to-column connections to measure the joints' rotation (Fig. 17a, b

Table 6

Load-vertical displacement of the central column at the end of each phase.

\begin{tabular}{lll}
\hline Testing phase & Load $(\mathrm{kN})$ & Vertical displacement $(\mathrm{mm})$ \\
\hline End of propping system removal & 228.55 & 0.00 \\
End of loading phase & 669.25 & 0.00 \\
End of column removal & 2.81 & 154.60 \\
End of stabilization phase & 2.02 & 163.80 \\
End of the test & -300.85 & 304.30 \\
\hline
\end{tabular}

(b)

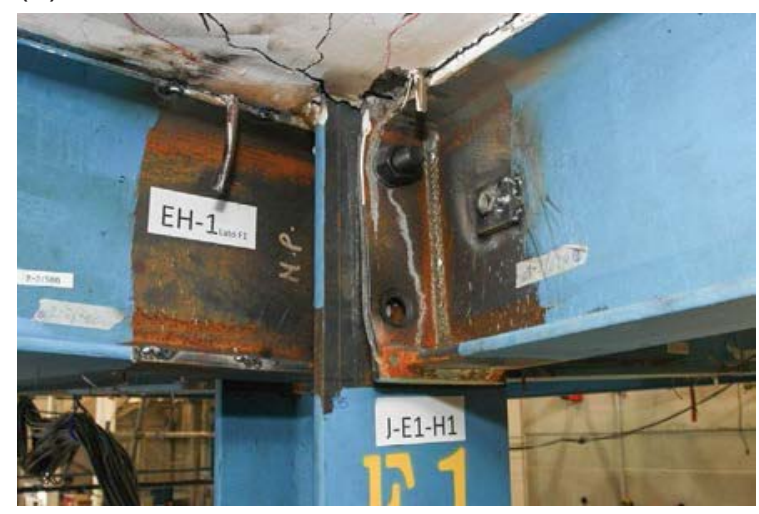

Fig. 22. The central node at collapse. 
(b)

(a)
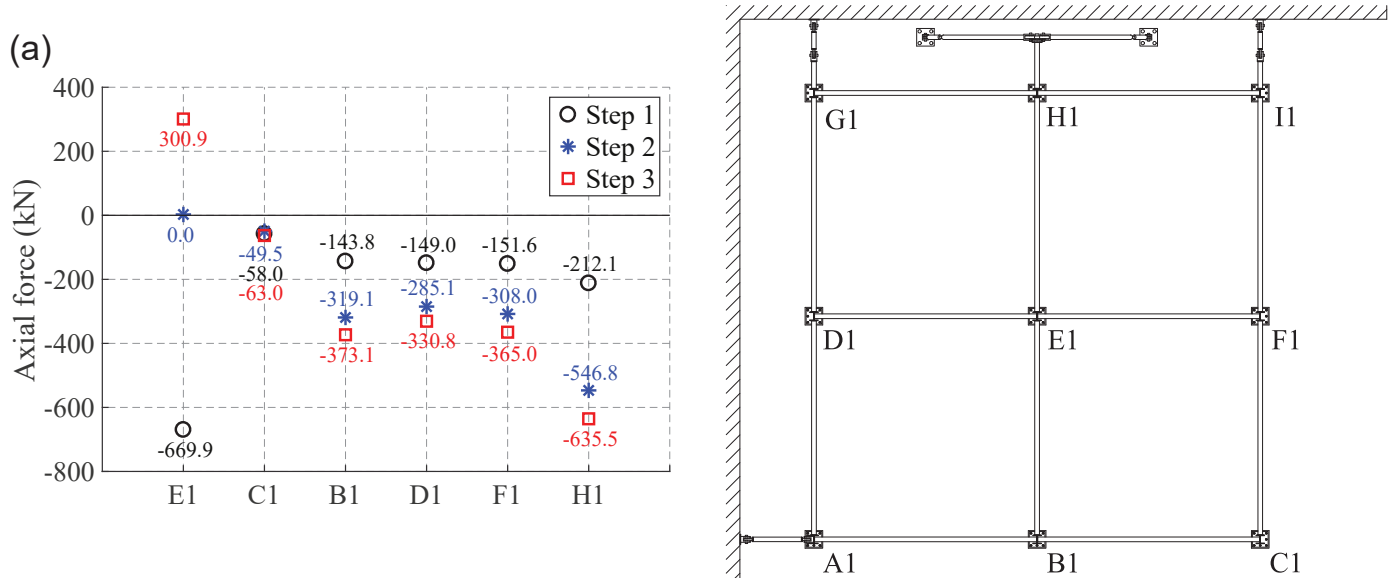

Fig. 23. Axial force in the columns.

(a)

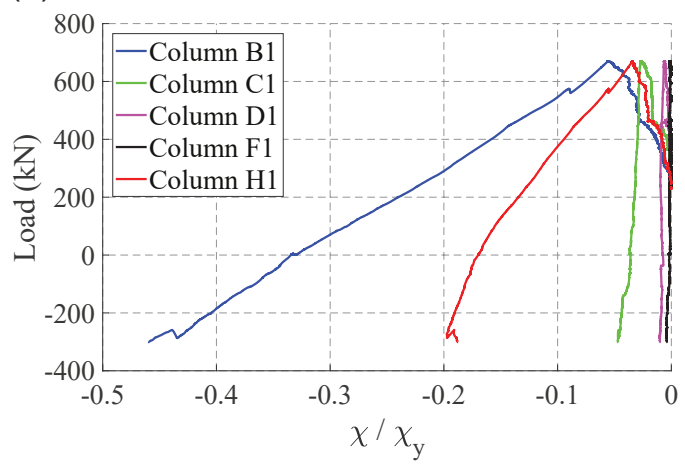

(b)

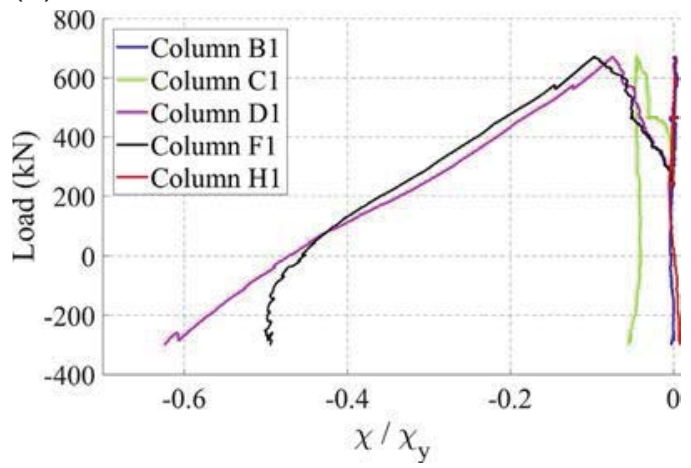

Fig. 24. Curvature of the columns.

respectively). Further LVDTs allowed monitoring the torsional rotation of six external beams (Fig. 18a) and the rotation of the columns in correspondence with the beams connection (Fig. 18b). Finally, a wire transducer measured the vertical displacement at the central node of the specimen and a load cell the force acting on the central column. The vertical displacement of the central points of the slab panels were monitored. Table 4 summarizes the instrumentation set-up and the parameters measured. The frequency of data logging was kept at $2 \mathrm{~Hz}$.

\subsection{The testing procedure}

The test comprises the following phases, as illustrated in Fig. 19. At first, the hydraulic jack was activated and the propping system removed. Afterwards, live loads were applied onto the slab by using bags filled with sand to approximate the uniform factored design load of $9.0 \mathrm{kN} / \mathrm{m}^{2}$. This load takes account of finishes, partitions and variable loads, and defines the condition before the column's collapse. Each bag was weighted before being placed on the slab surface in two layers. The first layer was uniformly distributed on the complete surface of the slab $\left(153.26 \mathrm{~m}^{2}\right)$, while the second layer acts onto the smaller area as illustrated in Fig. 20a. Table 5 reports the values of the loading applied by each layer. Step 2 simulated the column removal by reducing the hydraulic pressure of the jack down to zero. Finally, after a stabilization phase, in Step 3 a tensile force was applied at the central node in a displacement control mode by means of the actuator, and incremented up to the 'collapse'. The aim was to quantify the residual strength of the structure after column removal. When two bolts in one endplate
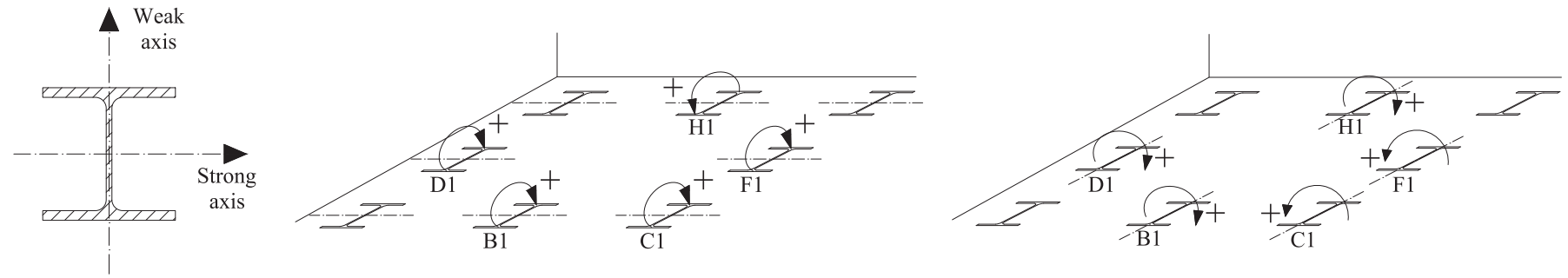

Fig. 25. Positive sign of columns curvature. 
(a)

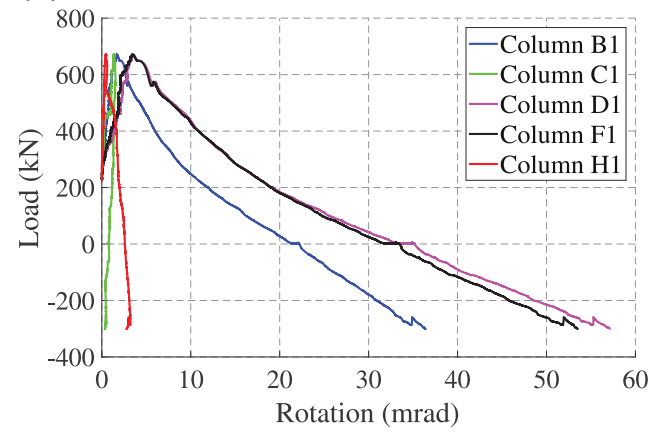

(b)

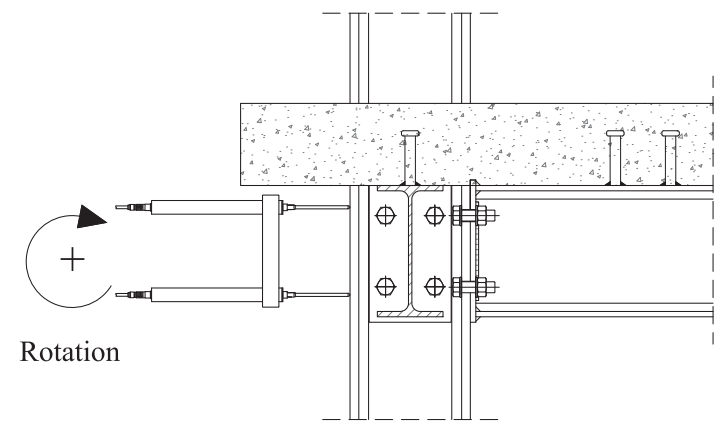

Fig. 26. External columns rotation at the beam level.

(a)

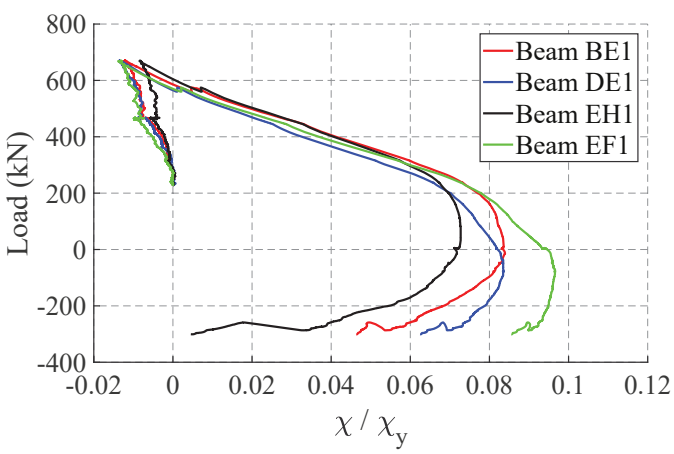

(b)

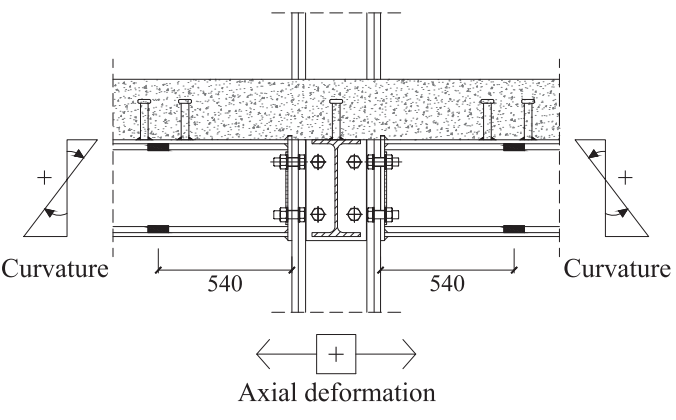

Fig. 27. Curvature of the central beams near the central node

joint of the central node fractured, the 'collapse condition' was assumed to have been achieved, and the test stopped.

\section{Test results}

\subsection{The overall response}

As a first appraisal of the frame response, Fig. 21 reports the load versus vertical displacement curve of the 'central column'. At the end of the propping system removal, the vertical reaction force, due to the self-weight of the structure, was equal to $228.55 \mathrm{kN}$. When the structure was completely loaded (end of Step 1), this reaction force increased up to $669.25 \mathrm{kN}$. The hydraulic pressure of the jack was then gradually reduced (Step 2) and at the end of the column removal, the vertical displacement of the central node was of

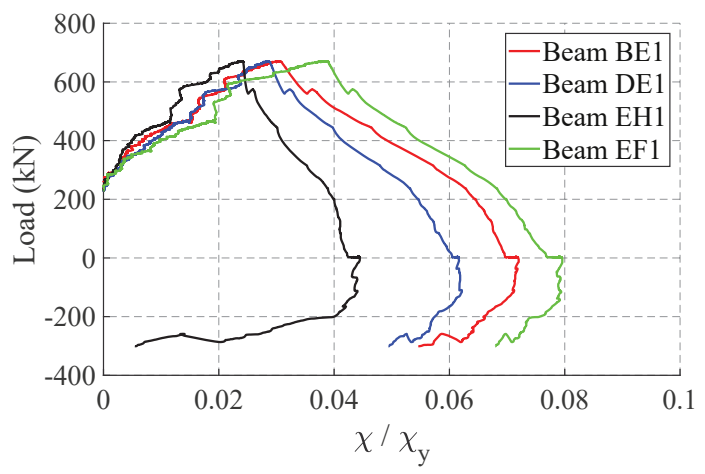

Fig. 28. Curvature of the central beams at mid-span.
$154.60 \mathrm{~mm}$. The specimen was left stabilizing for two hours. During this phase, the deflection of the central node increased up to $163.80 \mathrm{~mm}$. Finally, a tensile force was applied by means of the actuator (Step 3). The subsequent fracture of two bolts of the connection between the central column and the beam EH1, identified by points A and B in Fig. 21, pointed clearly out the lack of incremental strength in that joint (Fig. 22). Due also to the state of 'distress' of the concrete at the central node it was decided for safety to stop the test. At this stage, the applied tensile load was $300.85 \mathrm{kN}$ and the vertical displacement was $304.30 \mathrm{~mm}$. Vertical displacements of the slab panels are comparable between them, pointing out the symmetry of the frame response. Therefore, the curve in Fig. 21 can be assumed to describe the overall response. In Table 6 the values of the load and deflection at the end of the main test phases are summarized.

\subsection{Critical component and failure mode}

The response in the three loading phases pointed clearly out the importance of the beam-to-column joints and of the concrete slab. More details on the performance of the various frame components are gathered in the following sections. As a general feature:

I) extensive cracking of the concrete evolved during the loading steps, providing a picture of the resistance mechanism of the slab;

II) inelastic behaviour developed in the vicinity of the beam-to-column joints, where significant deformations of the endplates, of the column web panels, of the steel beams and of the rebars were observed and measured;

III) splitting of the slab occurred at the back of the joints at the external columns. 
(a)

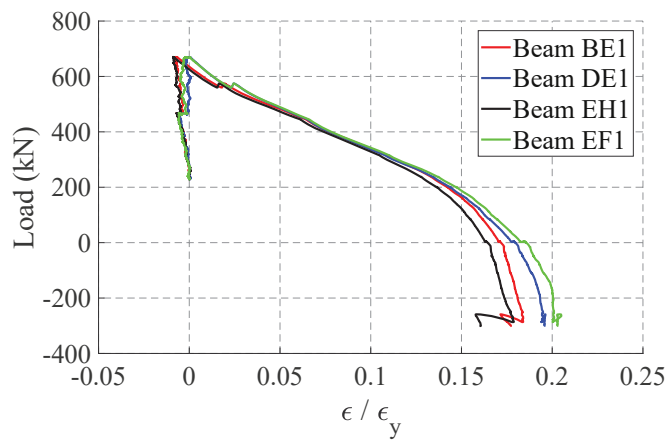

(b)

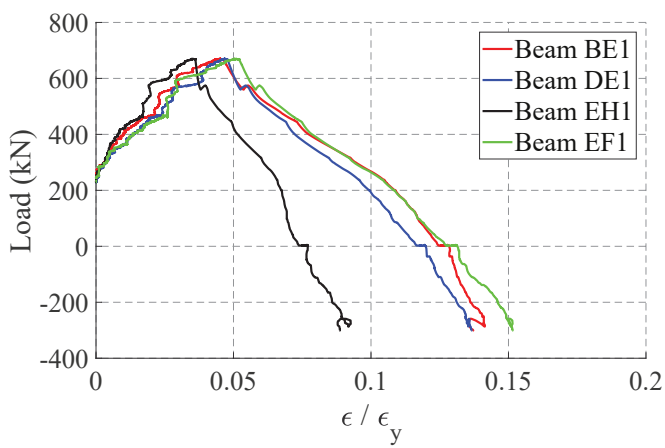

Fig. 29. Mean axial strain of the central beams.

(a)

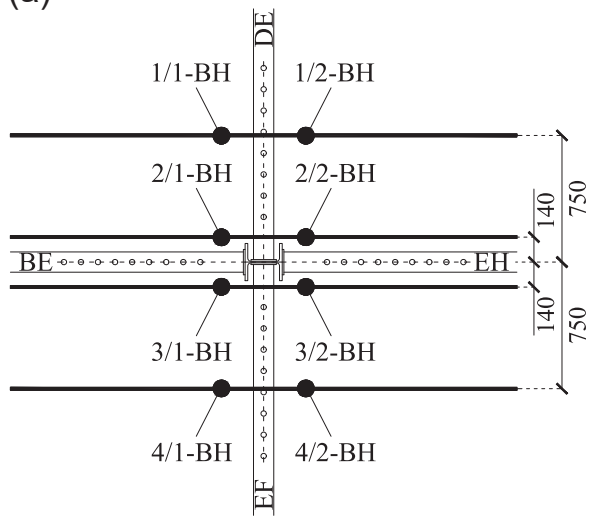

(b)

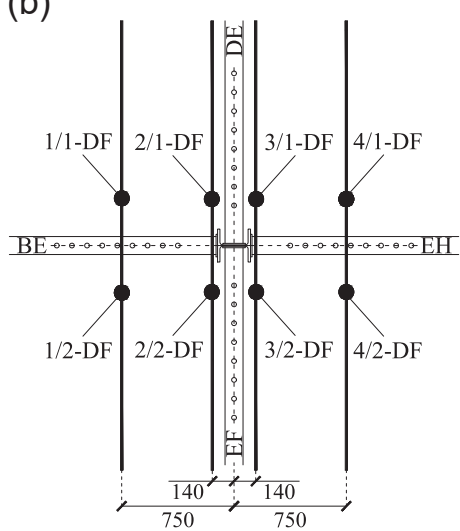

Fig. 30. Strain gauges on the rebars

The joints remarkably contribute to the load redistribution in case of a column loss up to the development of the catenary action in the internal beams. The joints at the central node reached important rotations and axial force demands, as confirmed by the results in the central beams (Section 5.3.2), and have turned out as the most critical elements. The performance of the steel connections are consistent with the studies carried out by Yang and Tan [15], who tested common types of bolted-steel beam-to-column connections under a centralcolumn-loss scenario in 2D frames. Endplate bolted connections are widely used in steel framing because of ease in fabrication and advantages in terms of erection speed. The research work on T-stub elements provides useful information about reliable endplate design.
Complementary tests on T-stubs extracted from the sub-frames connections were performed as part of the 'Robustimpact' project [59].

\subsection{The frame components}

\subsubsection{The columns}

The strain gauges installed at the five instrumented column bases allow determining the average axial strain and, assuming the material as elastic, the axial force. Fig. 23 reports such values of the axial forces together with the forces acting on the 'central column' E1 at the end of each loading step. The redistribution of the load from the central to the other columns is apparent. As a result, columns B1, D1 and F1 (a)

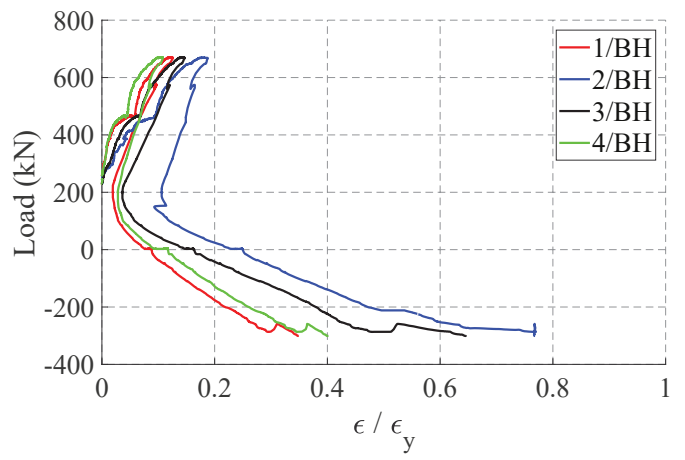

(b)

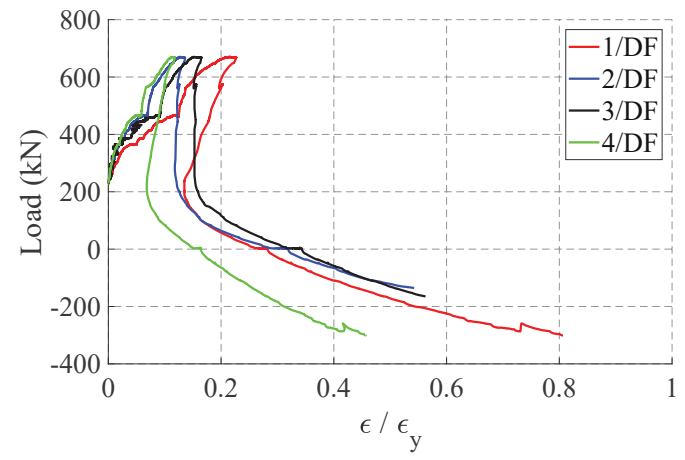

Fig. 31. Axial strain of the rebars. 


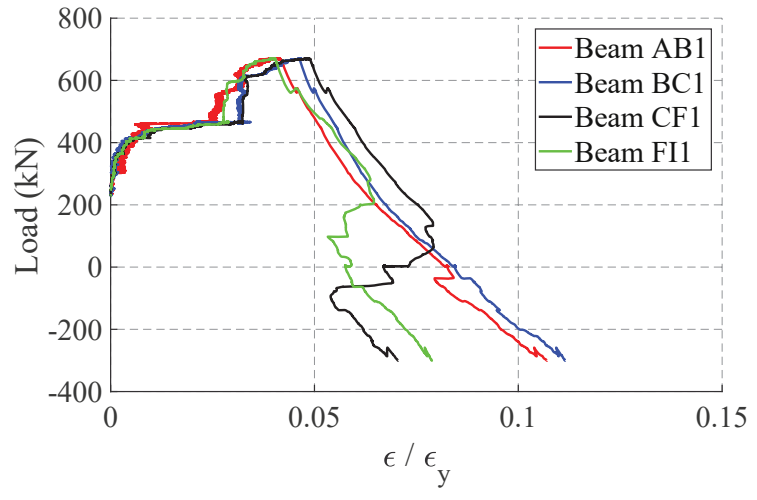

Fig. 32. Axial strain of the lateral beams.

carried about twice the axial force acting before the column removal. The axial force increase in column $\mathrm{H} 1$ was the greatest due to the nearby restraining system br.H1, simulating the continuity with the adjacent part of the frame. On the contrary, the corner column C1 had a very limited axial load variation due to the effect of the concrete slab action.

As to the bending response, Fig. 24 reports the curvature $\chi$ at the column base (normalised on the curvature associated with the elastic limit moment $\chi_{y}=13.77 \cdot 10^{-6} 1 / \mathrm{mm}$ ) about both the strong axis (Fig. 24a) and the weak axis (Fig. 24b) with respect to the axial load in the central column. The external columns connected with the lost column experienced the greatest increase of curvature, and hence of bending moment. The curvature of corner column $\mathrm{C} 1$ remains modest in both planes. However, all the columns remain elastic up to 'collapse'. Fig. 25 illustrates the positive curvature assumptions.

Displacement transducers allow determining the columns rotation at the beam level (Fig. 26). This rotation is the end result of the local deformation (column web panel) and of the global deflection. Higher rotations are determined for columns B1, D1 and F1. The curves related to columns D1 and F1 are fairly close to each other pointing out the symmetric 'transverse' response. The counteracting effect of the truss system br.H1 limits column $\mathrm{H} 1$ rotations while the corner column $\mathrm{C} 1$ remained mainly undeformed.

\subsubsection{Steel beams and rebars}

The central steel beams are instrumented with strain gauges near the central node and at mid-span. Measured data allow for an appraisal of the beams' behaviour. As to the curvature (positive as illustrated in Fig. 27b), Fig. 27a shows the change of the bending moments from negative to positive when the central column is removed. At mid-span (Fig. 28) the steel section remains in tension during the whole duration

(a)

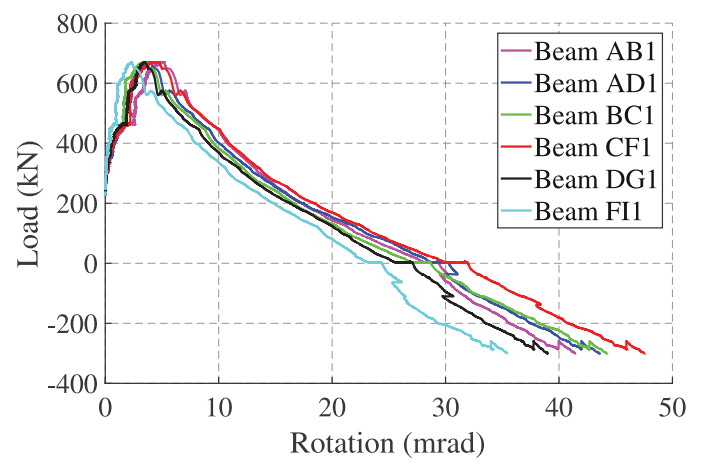

of the test. The curvature evolution depends on two factors: the reduction of the stiffness of the central joints and the straightening of the steel section associated with increasing importance of the axial force, with the latter effect becoming dominant in the last phase. The mean axial strains plotted in Fig. 29 show their continuous grow up. Such a trend reveals that a catenary action starts to be activated. A consistent information at the central node is provided by the evaluation of the axial strains in the instrumented reinforcement bars (Fig. 30). Fig. 31 shows the average axial strains measured on two strain gauges placed on the same rebar symmetrically with respect to the column. For instance, the curve 1/BH (in Fig. 31a) refers to the average axial strain between 1/1-BH and 1/2-BH as reported in Fig. 30a. Strains are normalised on the yielding strain of $2615 \mu \varepsilon$ based on the mean yield stress in Table 2. Differences between the results in the same bar were limited. During the application of the tensile force by the actuator, some bars almost reached the yielding force (note that in some rebars strain gauges did not work properly up to the end of the test). These data seem to point out that the Eurocode value of the effective width in the vicinity of the joint is conservative.

Focusing on the lateral beams: i) the axial force close to the midspan is tensile and increases as illustrated in Fig. 32, ii) remarkable torsional rotations (Fig. 33) develop during the loading phases of column removal and tensile force application. This deformation pattern points out clearly the important role of the slab in making the alternative loading path possible. An adequate anchorage of the slab to the lateral beams by means of shear connectors has hence to be guaranteed in design.

\subsubsection{The beam-to-column joints}

Inclinometers and displacement transducers installed in the vicinity of the beam-to-column nodes enabled measurement of the joints rotation. Fig. 34 provides the joint nomenclature and the conventional moment and rotation sign. As to the internal joints, Fig. 35a, it is apparent the sign reversal of the rotation associated with the column removal, leading to the change from hogging to sagging bending moment in all connections at the central node, well before the full unloading. The curves related to joints B and D confirm the symmetry of the transverse behaviour. The influence of the frame continuity explains the difference in joints $A$ and $C$, to which increases the ductility demand. The plastic deformation of the endplates was the main source of the significant rotation capacity (Fig. 22). As expected, the external joints (Fig. 35b) showed a continuous increase of rotation. The rotation of the joints $F$ is not reported in the Step 3 of the test due to an instrument malfunction. The deformation of the web panel in shear (Fig. 36a), and the plastic instability of the bottom flange (beam EH1, Fig. 36b) were the main sources of joint rotation. A further contribution came from the local deformation of the slab in the vicinity of the external column (Fig. 39).

(b)

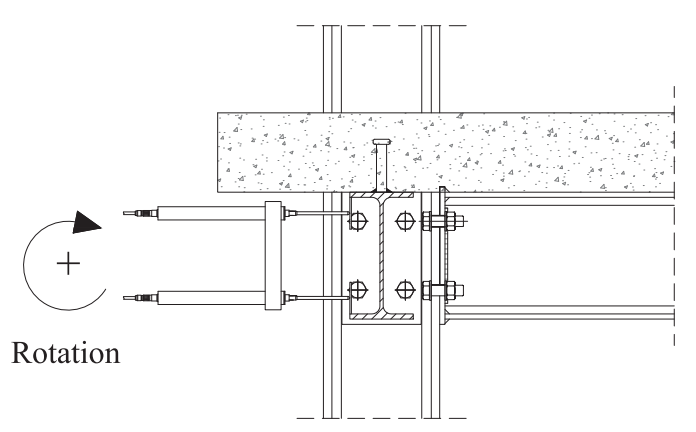


(a)

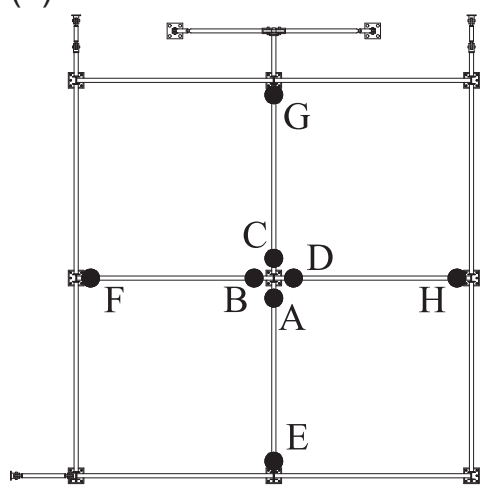

(b)

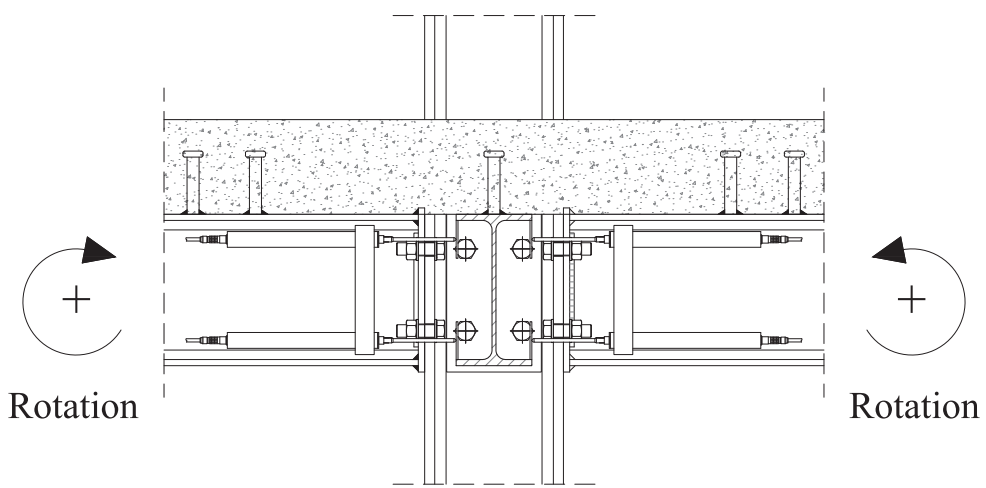

(c)

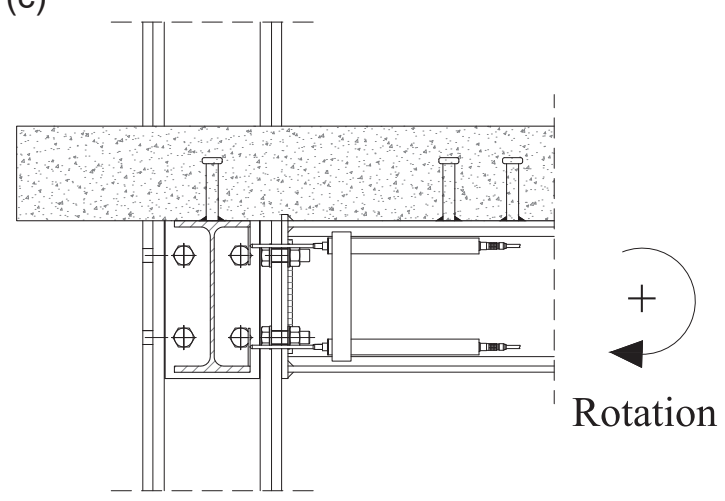

Fig. 34. Joints and positive sign of rotation.

It is interesting to note that joints designed as ductile under monotonic loading were able to achieve important plastic rotations also under the combination of sagging moments and tension axial forces associated with the column loss.

\subsubsection{The restraints}

In Fig. 37 the axial forces in the restraining members connecting the frame to the counter walls and the strong floor are plotted. The inclined bracings (br.H1G and br.H1I in Fig. 13) are the most stressed: they are in tension due to the vicinity of column $\mathrm{H} 1$ and the continuity with the beam EH1. The horizontal restraints (br.A1, br.G1 and br.I1 in Fig. 13) are subject to very low compression forces, stemming from preventing the in-plane movement at the floor level.

(a)

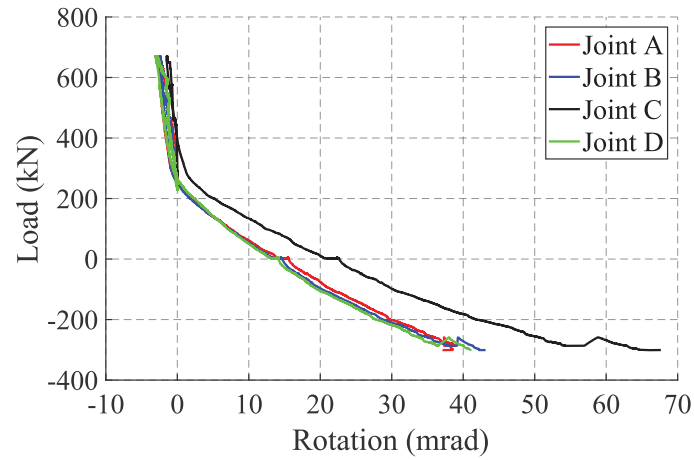

\subsubsection{The slab}

The cracking pattern revealed the slab key role in all the test phases. In particular, the cracking pattern (Fig. 38) evolved from that typical for a continuous plate under vertical loads (Step 1) to that of a plate where membrane actions start to be activated (Step 3). After the column removal, on the bottom side of the slab (Fig. 38a), cracks were positioned along the diagonals of the four panels slab, while on the top side (Fig. 38b) the cracking pattern reveals a compressive concentric rings around the central column. This picture provides important information for the development of simplified 3D slab models to capture the membrane action. These results are in accordance with the findings of studies on the robustness of RC buildings. Cracks in correspondence of the lateral columns (Fig. 39) showed the significant importance of the mechanism of force transmission from the slab to the column. To allow an

(b)

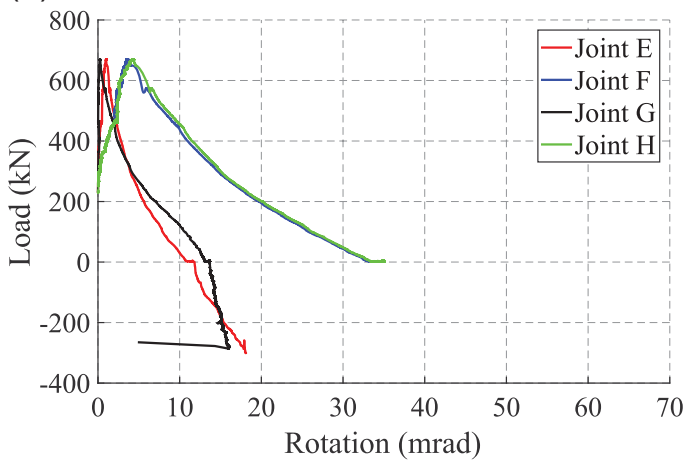

Fig. 35. Joints rotation 
(a)

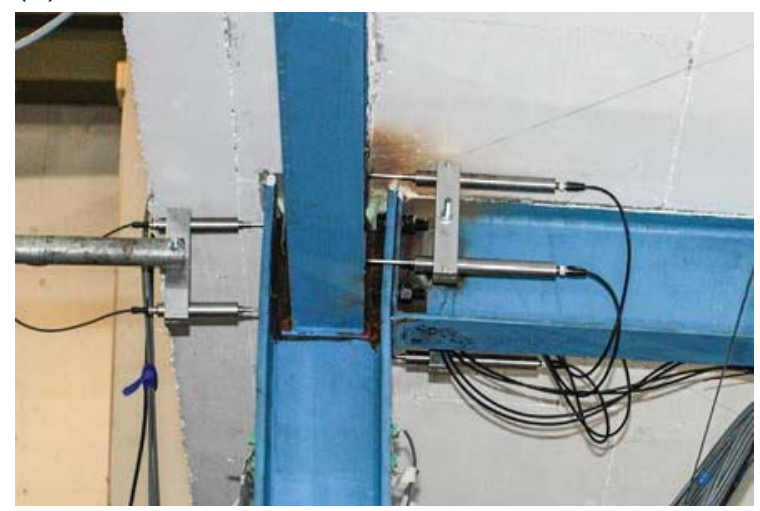

(b)

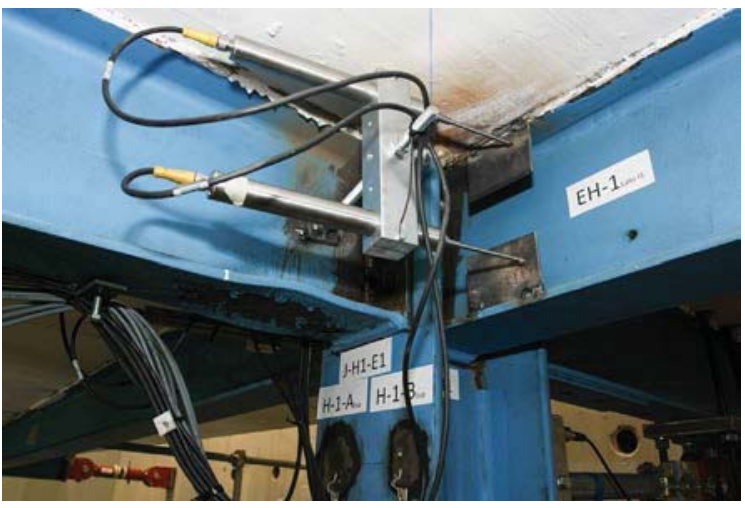

Fig. 36. Joints $E$ and $G$ at the end of the test.

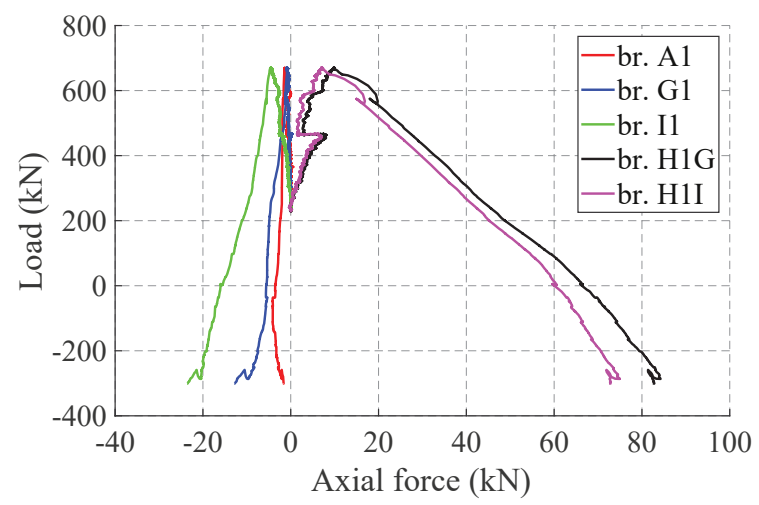

Fig. 37. Axial force in the lateral restraints.

adequate mechanism of force transmission, detail rules for the design of the rebars have hence to be adopted $[60,61]$.

\section{Summary and conclusions}

This paper presents an experimental study carried out at the University of Trento in the framework of a European project on robustness of steel-concrete composite frames. The study comprises two full-scale tests on sub-frames 'extracted' from reference buildings designed according to the Eurocodes. The sub-frames were two-bays by two-bays in plan and one storey in height. A suitable restraining system was designed in order to adequately simulate the interaction between the sub-frame and the full-frame. The specimens were subjected to the loss of the central column in order to investigate the role of the concrete slab and of the beam-to-column joints in developing an alternate loading path, preventing the progressive collapse. This paper reports the outcomes of the first test on the sub-frame characterised by a symmetric configuration.

A three steps loading sequence was adopted: first the full factored design loads was applied onto the slab, the collapse of the central column was then simulated and, finally, a tensile force was applied at the central column in order to appraise the residual strength of the structure. When two bolts in one endplate joint of the central node fractured, the 'collapse condition' was assumed to have been achieved, and the test stopped. The plastic deformation of the endplates was the main source of the significant rotation capacity of the central joints (up to $67 \mathrm{mrad}$ ) supporting the study by Yang and Tan [15] of flush endplate connections. Lateral joints did not fail: their deformation was associated with the plasticity of the web panel in shear, the plastic instability of the bottom flange of the steel beam and the local deformation of the slab. In particular, the slab split behind the joints with external columns due to the activation of a mechanism of force transmission from the slab to the column. However, it is interesting to note that joints designed as ductile under monotonic loading were able to achieve important plastic rota- (a)

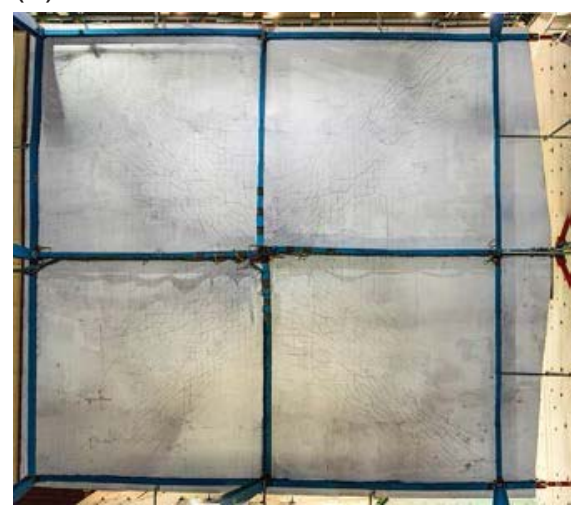

(b)

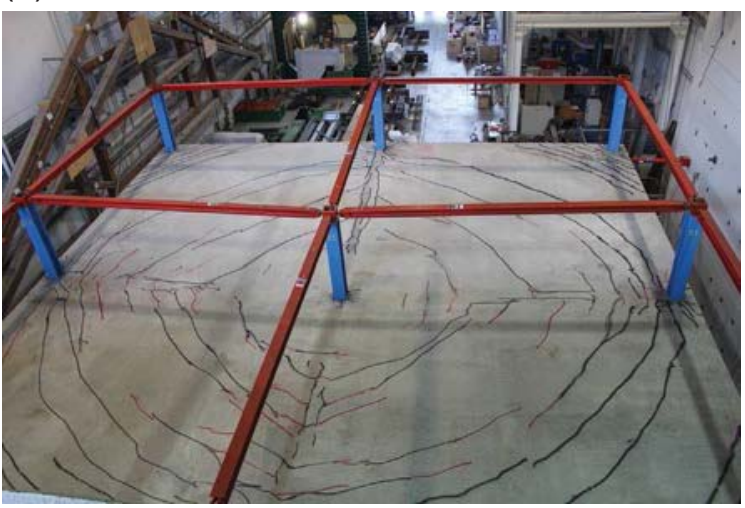

Fig. 38. Cracking pattern of the slab. 

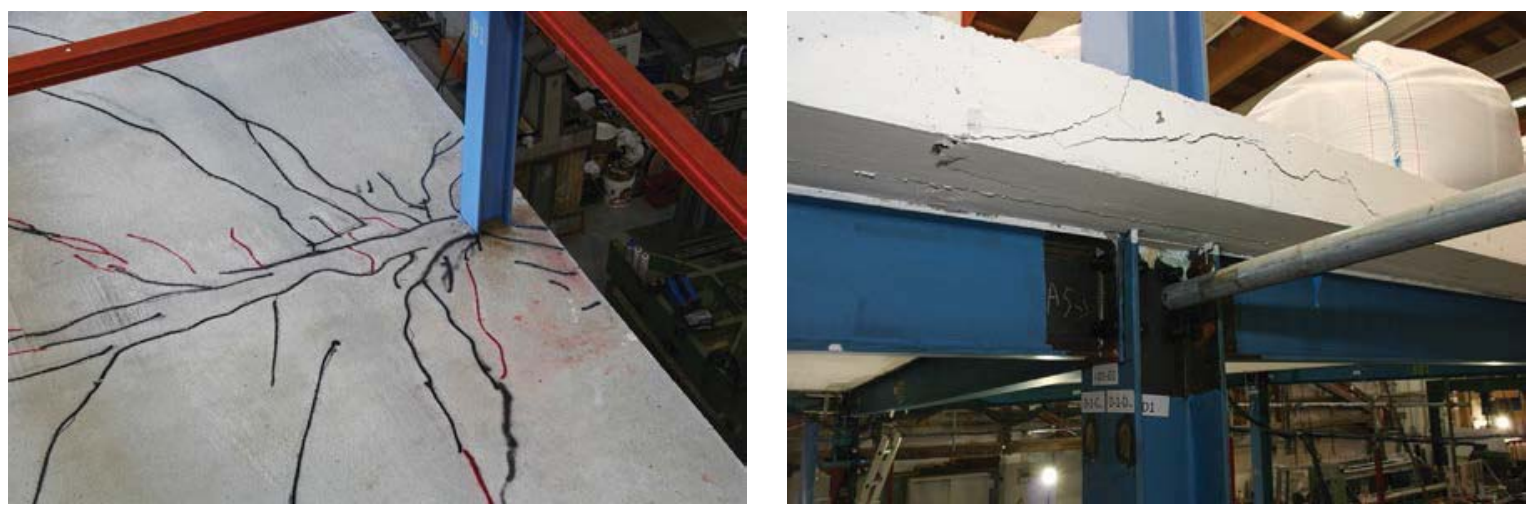

Fig. 39. Cracks in the slab thickness in the vicinity of the external columns.

tions also under the combination of sagging moments and tensile axial forces associated with the column loss scenario.

The collapse was achieved before the membrane action of the slab was fully activated. Nevertheless, the slab significantly contributed to the load redistribution from the damaged to the undamaged parts of the structure. The evolution of the cracking pattern in the three stages of loading revealed the different slab role in the various phases, providing important information for the development of 3D design models allowing catching also the membrane action. After the column removal, on the bottom side of the slab, cracks were positioned along the diagonals of the four panels slab, while on the top side the cracking pattern revealed compressive concentric rings around the central column, typical of slabs where membrane forces started to be activated. These results are in accordance with the findings of studies of the robustness of RC buildings. Remarkable torsional rotations of the external beams during the loading phases of column removal and tensile force application were observed. This is a further index of the slab action making the alternative loading path possible. As a general outcome, the test pointed out that adequate design of robust composite structures should account for all the various local phenomena affecting joint ductility and appropriately incorporate detailing rule to ensure the required slab response, e.g. by providing an adequate anchorage of the slab to the lateral beams by means of shear connectors.

The test's data made possible to calibrate a refined FE Abaqus model [62]. Numerical analyses confirmed the good overall performance of the specimen, showing that the applied tensile load at collapse is associated with a residual strength of about $30 \%$ in terms of the design factored load applied on the slab.

On the one hand, the outcomes of the test confirmed that the Eurocodes specifications are a good base for the design of robust 3D composite frames. However, it underlined that an enhancement of joint and slab detailing and design is still needed.

\section{Acknowledgments}

The study was made possible by funds of the Research Fund for Coal and Steel of the European Community (Contracts number No. RFSR-CT2004-00046 and No. RFSR-CT-2012-00029), which the Authors gratefully acknowledge. The Authors want also to thank the work of Stefano Girardi, Marco Graziadei and Alessandro Banterla who followed the difficult Laboratory work.

\section{References}

[1] S. El-Tawil, H. Li, S. Kunnath, Computational simulation of gravity-induced progressive collapse of steel-frame buildings: current trends and future research needs, J. Struct. Eng. 140 (8) (2014), A2513001.
[2] GSA, Progressive Collapse Analysis and Design Guidelines for New Federal Office Buildings and Major Modernization Projects, General Service Administration, USA, 2003.

[3] DoD, Unified Facilities Criteria (UFC), Design of building to resist progressive collapse, Unified Facilities Crtiteria (UFC) 4-023-03, Department of Defense, USA, 2009. [4] Office of the Deputy Prime Minister, The building regulations 2000, Part A, Schedule 1:A3, Disproportionate Collapse, London, UK, 2004

[5] EN 1991-1-7, Eurocode 1: Actions on structures - part 1-7: General actions - Accidental actions, European Committee for Standardization, Brussels, 2006

[6] BS, BS5950, Structural Use of Steelwork in Buildings, Part 1: Code of Practice for Design - Rolled and Welded Sections, British Standard Institute, London, UK, 2001.

[7] BS, BS6399, Loading for Buildings, Part 1: Code of Practice for Dead and Imposed Loads, British Standard Institute, London, UK, 1996.

[8] B.A. Izzuddin, A.G. Vlassis, A.Y. Elghazouli, D.A. Nethercot, Progressive collapse of multi-storey buildings due to sudden column loss - part I: simplified assessment framework, Eng. Struct. 30 (2008) 1308-1318.

[9] A.G. Vlassis, B.A. Izzuddin, A.Y. Elghazouli, D.A. Nethercot, Progressive collapse of multi-storey buildings due to sudden column loss - part II: application, Eng. Struct 30 (2008) 1424-1438.

[10] U. Kuhlmann, L. Rölle, J.P. Jaspart, J.F. Demonceau, O. Vassart, K. Weynand, C. Ziller, E. Busse, M. Lendering, R. Zandonini, N. Baldassino, Robust structures by joint ductility, Final Report, Research Fund for Coal and Steel Series N. EUR 23611 EN, European Commission, Luxembourg, 2009

[11] J.F. Demonceau, J.P. Jaspart, Experimental test simulating a column loss in a composite frame, Adv. Steel Constr. 6 (3) (2010) 891-913.

[12] B. Yang, K.H. Tan, Behavior of composite beam-column joints in a middle-columnremoval scenario: experimental tests, J. Struct. Eng. ASCE 140 (2) (2014), 04013045.

[13] S.A. Oosterhof, R.G. Driver, Behavior of steel shear connections under columnremoval demands, J. Struct. Eng. 141 (4) (2015), 4014126.

[14] L. Li, W. Wang, Y. Chen, Y. Lu, Effect of beam web bolt arrangement on catenary behaviour of moment connections, J. Constr. Steel Res. 104 (2015) 22-36.

[15] B. Yang, K.H. Tan, Experimental tests of different types of bolted steel beam-column joints under a central-column removal scenario, Eng. Struct. 54 (2013) 112-130.

[16] J.M. Weigand, J.W. Berman, Integrity of bolted angle connections subjected to simulated column removal, J. Struct. Eng. 142 (3) (2016), 4015165.

[17] H.S. Lew, J.A. Main, S.D. Robert, F. Sadek, V.P. Chiarito, Performance of steel moment connections under a column removal scenario. I: experiments, J. Struct. Eng. 139 (1) (2013) 98-107.

[18] B. Yang, T.K. Hai, Robustness of bolted-angle connections against progressive collapse: experimental tests of beam-column joints and development of componentbased models, J. Struct. Eng. ASCE 139 (9) (2013) 1498-1514.

[19] L. Guo, S. Gao, F. Fu, Structural performance of semi-rigid composite frame under column loss, Eng. Struct. 95 (2015) 112-126.

[20] L. Guo, S. Gao, Y. Wang, S. Zhang, Tests of rigid composite joints subjected to bending moment combined with tension, J. Constr. Steel Res. 95 (2014) 44-55.

[21] W. Wang, J. Wang, X. Sun, Y. Bao, Slab effect of composite subassemblies under a column removal scenario, J. Constr. Steel Res. 129 (2017) 141-155.

[22] B. Yang, T.K. Hai, G. Xiong, S.D. Nie, Experimental study about composite frames under an internal column-removal scenario, J. Constr. Steel Res. 121 (2016) 341-351.

[23] L. Guo, S. Gao, F. Fu, Y. Wang, Experimental study and numerical analysis of progressive collapse resistance of composite frames, J. Constr. Steel Res. 89 (2013) 236-251.

[24] F. Sadek, J.A. Main, H.S. Lew, Y. Bao, Testing and analysis of steel and concrete beamcolumn assemblies under a column removal scenario, J. Struct. Eng. 137 (9) (2011) 881-892.

[25] S. Donahue, M. Hadjioannou, E.B. Williamson, M. Engelhardt, B.A. Izzuddin, D. Nethercot, H.Z. Jahromi, D. Stevens, K. Marchand, M. Waggoner, Experimental evaluation of floor slab contributions in mitigating progressive collapse of steel structures, Proceedings of the $5^{\text {th }}$ International Conference on Safety and Security Engineering (SAFE 2013), Rome, vol. 134, 2013, pp. 615-626, Sept. $17^{\text {th }}-19^{\text {th }}$

[26] F. Dinu, I. Marginean, D. Dubina, I. Petran, Experimental testing and numerical analysis of 3D steel frame system under column loss, Eng. Struct. 113 (2016) 59-70. 
[27] S.J. Foster, C.G. Bailey, I.W. Burgess, R.J. Plank, Experimental behaviour of concrete floor slabs at large displacements, Eng. Struct. 26 (2004) 1231-1247.

[28] K. Qian, B. Li, Slab effects on the response of reinforced concrete substructures after loss of corner column, ACI Struct. J. 109 (6) (2012) 845-856.

[29] K. Qian, B. Li, Quantification of slab influences on the dynamic performance of RC frames against progressive collapse, J. Perform. Constr. Facil. 29 (1) (2015), 04014029 .

[30] P.Q. Ren, Y. Li, X.Z. Lu, Y.L. Zhou, Experimental investigation of progressive collapse resistance of one-way reinforced concrete beam-slab substructures under a middlecolumn-removal scenario, Eng. Struct. 118 (2016) 28-40.

[31] H.Z. Jahromi, B.A. Izzuddin, D.A. Nethercot, S. Donahue, M. Hadjioannou, E.B. Williamson, M. Engelhardt, D. Stevens, K. Marchand, M. Waggoner, Robustness assessment of building structures under explosion, Buildings 2 (2012) 497-518.

[32] ASCE, Minimum design loads for buildings and other structures, SEI/ASCE 7-10, Reston, VA, 2010.

[33] E.S. Johnson, J.E. Meissner, L.A. Fahnestock, Experimental behavior of a half-scale steel concrete composite floor system subjected to column removal scenario, J. Struct. Eng. 142 (2) (2016) 1-12 04015133.

[34] S. Kim, C.Ho Lee, Effects of floor slab on progressive collapse resistance of steel moment frames, J. Constr. Steel Res. 110 (2015) 182-190.

[35] P.X. Dat, T.K. Hai, Membrane actions of RC slabs in mitigating progressive collapse of building structures, Eng. Struct. 55 (2013) 107-115.

[36] L. Kwasniewski, Nonlinear dynamic simulations of progressive collapse for a multistory building, Eng. Struct. 32 (2010) 1223-1235.

[37] F. Fu, Progressive collapse analysis of high-rise building with 3-D finite element modelling method, J. Constr. Steel Res. 65 (2009) 1269-1278.

[38] H. Li, S. El-Tawil, Three-dimensional effects and collapse resistance mechanisms in steel frame buildings, J. Struct. Eng. 140 (8) (2014), A4014017.

[39] F. Sadek, S. El-Tawil, H.S. Lew, Robustness of composite floor systems with shear connections: modeling, simulation, and evaluation, J. Struct. Eng. 134 (11) (2008) 1717-1725.

[40] Y. Alashker, S. El-Tawil, F. Sadek, Progressive collapse resistance of steel-concrete composite floors, J. Struct. Eng. 136 (10) (2010) 1187-1196.

[41] J.A. Main, Composite floor systems under column loss: collapse resistance and tie force requirements, J. Struct. Eng. 140 (8) (2014), A4014003.

[42] H.Z. Jahromi, A.G. Vlassis, B.A. Izzuddin, Modelling approaches for robustness assessment of multi-storey steel-composite buildings, Eng. Struct. 51 (2013) 278-294.

[43] A.G. Vlassis, B.A. Izzuddin, A.Y. Elghazouli, D.A. Nethercot, Progressive collapse of multi-storey buildings due to failed floor impact, Eng. Struct. 31 (2009) 1522-1534.

[44] P.M. Stylianidis, D.A. Nethercot, B.A. Izzuddin, A.Y. Elghazouli, Robustness assessment of frame structures using simplified beam and grillage models, Eng. Struct. 115 (2016) 78-95.

[45] P.M. Stylianidis, D.A. Nethercot, B.A. Izzuddin, A.Y. Elghazouli, Study of mechanics of progressive collapse with simplified beam models, Eng. Struct. 117 (2016) 287-304.
[46] P.M. Stylianidis, D.A. Nethercot, B.A. Izzuddin, A.Y. Elghazouli, Modelling of beam response for progressive collapse analysis, Struct 3 (2015) 137-152.

[47] European Commission - Research Programme of the Research Fund for Coal and Steel, Robust impact design of steel and composite building structures, 'RobustImpact'. Grant Agreement Number RFSR-CT-2012-00029, Final Report, 2019.

[48] EN 1993-1-8, Eurocode 3: Design of Steel Structures - part 1-8: Design of joints, European Committee for Standardization, Brussels, 2005.

[49] EN 1991-1-1, Eurocode 1: Actions on Structures - Part 1-1: General Actions, Densities, Self-Weight, Imposed Loads for Buildings, European Committee for Standardization, Brussels, 2004.

[50] EN 1992-1-1, Eurocode 2: Design of Concrete Structures - Part 1-1: General Rules and Rules for Buildings, European Committee for Standardization, Brussels, 2004.

[51] EN 1993-1-1, Eurocode 3: Design of Steel Structures - Part 1-1: General Rules and Rules for Buildings, European Committee for Standardization, Brussels, 2005.

[52] EN 1994-1-1, Eurocode 4: Design of Composite Steel and Concrete Structures - Part 1-1: General Rules and Rules for Buildings, European Committee for Standardization, Brussels, 2004

[53] N. Baldassino, F. Freddi, R. Zandonini, Moment Resisting Steel-Concrete Composite Frames under the Column Loss Scenario: Design of the Reference Frames and of the Full-Scale Sub-Frame Specimens, Research report of the Department of Civil, Environmental and Mechanical Engineering, University of Trento, 2018.

[54] CSI SAP2000, Linear and Nonlinear Static and Dynamic Analysis and Design of Three-Dimensional Structures: Basic Analysis Reference Manual, Computer and Structures, Inc, Berkeley, California, 2011.

[55] R. Zandonini, N. Baldassino, F. Freddi, Robustness of steel-concrete flooring systems - an experimental assessment, Stahlbau 83 (9) (2014) 608-613.

[56] Abaqus - Analysis User's Manual, Version 6.14. Simulia Dassault Systes2014.

[57] EN 12390-3, Testing Hardened Concrete - Part 3: Compressive Strength of Test Specimens, 2009.

[58] EN 12390-6, Testing Hardened Concrete - Part 6: Tensile Splitting Strength of Test Specimens, 2010.

[59] N. Baldassino, M. Bernardi, R. Zandonini, T-stub response and loading rate, Connections VIII 8th International Workshop on Connections in Steel Structures, Chicago: AISC - American Institute of Steel Construction, Eighth International Workshop on Connections in Steel Structures, Boston, USA 2016, pp. 589-598, (May $24^{\text {th }}-26^{\text {th }}$, 2016).

[60] EN 1998-1, Eurocode 8: Design of Structures for Earthquake Resistance - Part 1: General Rules, Seismic Actions and Rules for Building, European Committee for Standardization, Brussels, 2004

[61] W. Pardatscher, Modelling of the Response of Joints in Composite Steel Concrete Systems (in Italian), Master thesis University of Trento, 1995/1996.

[62] G. Roverso, Progressive Collapse Assessment of Steel and Concrete Composite Structures Subjected to Extreme Loading Conditions, PhD thesis, XXXI cycle University of Trento, 2019. 